INTERNATIONAL

\section{CENTER FOR}

PUBLIC POLICY
International Center for Public Policy

Working Paper 20-16

October 2020
COVID-19 Mortality and Contemporaneous Air Pollution

Wes Austin

Stefano Carattini

John Gomez Mahecha

Michael Pesko 



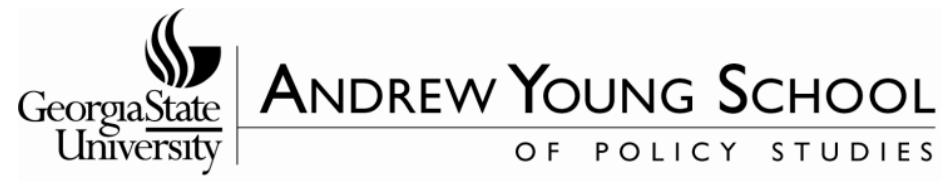

International Center for Public Policy

Working Paper 20-16

\section{COVID-19 Mortality and Contemporaneous Air Pollution}

\author{
Wes Austin \\ Stefano Carattini \\ John Gomez Mahecha \\ Michael Pesko
}

October

2020

International Center for Public Policy

Andrew Young School of Policy Studies

Georgia State University

Atlanta, Georgia 30303

United States of America

Phone: (404) 413-0235

Fax: (404) 651-4449

Email: paulbenson@gsu.edu

Website: http://icepp.gsu.edu/

Copyright 2020, the Andrew Young School of Policy Studies, Georgia State University. No part of the material protected by this copyright notice may be reproduced or utilized in any form or by any means without prior written permission from the copyright owner. 


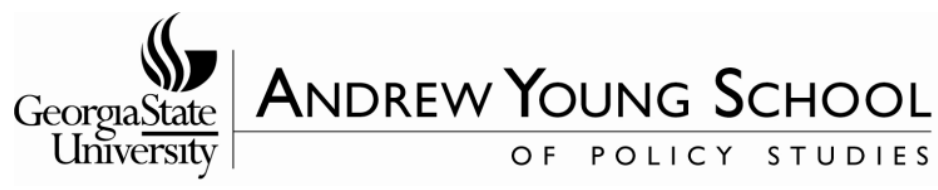

\section{International Center for Public Policy Andrew Young School of Policy Studies}

The Andrew Young School of Policy Studies was established at Georgia State University with the objective of promoting excellence in the design, implementation, and evaluation of public policy. In addition to four academic departments, including economics and public administration, the Andrew Young School houses eight leading research centers and policy programs, including the International Center for Public Policy.

The mission of the International Center for Public Policy (ICePP) at the Andrew Young School of Policy Studies is to provide academic and professional training, applied research, and technical assistance in support of sound public policy and sustainable economic growth in developing and transitional economies.

ICePP is recognized worldwide for its efforts in support of economic and public policy reforms through technical assistance and training around the world. This reputation has been built serving a diverse client base, including the World Bank, the U.S. Agency for International Development (USAID), the United Nations Development Programme (UNDP), finance ministries, government organizations, legislative bodies, and private sector institutions.

The success of ICePP reflects the breadth and depth of its in-house technical expertise. The Andrew Young School's faculty are leading experts in economics and public policy and have authored books, published in major academic and technical journals, and have extensive experience in designing and implementing technical assistance and training programs. Andrew Young School faculty have been active in policy reform in over 40 countries around the world. Our technical assistance strategy is not merely to provide technical prescriptions for policy reform, but to engage in a collaborative effort with host governments and donor agencies to identify and analyze the issues at hand, arrive at policy solutions, and implement reforms.

ICePP specializes in four broad policy areas:

- Fiscal policy (e.g., tax reforms, public expenditure reviews)

- Fiscal decentralization (e.g., reform, intergovernmental transfer systems, urban finance)

- Budgeting and fiscal management (e.g., local, performance-based, capital, and multiyear budgeting)

- Economic analysis and revenue forecasting (e.g., micro-simulation, time series forecasting)

For more information about our technical assistance activities and training programs, please visit our website at icepp.gsu.edu or contact us at paulbenson@gsu.edu. 


\title{
COVID-19 Mortality and Contemporaneous Air Pollution*
}

\author{
Wes Austin \\ Georgia State University \\ gaustin4@gsu.edu
}

\author{
Stefano Carattini \\ Georgia State University \\ scarattini@gsu.edu \\ Michael Pesko \\ Georgia State University \\ mpesko@gsu.edu
}

\author{
John Gomez Mahecha \\ Georgia State University \\ jgomezmahecha1@gsu.edu
}

October 1, 2020

\begin{abstract}
We examine the relationship between contemporaneous fine particulate matter exposure and COVID-19 morbidity and mortality using an instrumental variable approach based on wind direction. Harnessing daily changes in county-level wind direction, we show that arguably exogenous fluctuations in local air quality impact the rate of confirmed cases and deaths from COVID-19. In our preferred high dimensional fixed effects specification with state-level policy and social distancing controls, we find that a one $\mu \mathrm{g} / \mathrm{m}^{3}$ increase in PM 2.5 increases the number of confirmed cases by roughly $2 \%$ from the mean case rate in a county. These effects tend to increase in magnitude over longer time horizons, being twice as large over a 3-day period. Meanwhile, a one $\mu \mathrm{g} / \mathrm{m}^{3}$ increase in PM 2.5 increases the same-day death rate by $3 \%$ from the mean. Our estimates are robust to a host of sensitivity tests. These results suggest that air pollution plays an important role in mediating the severity of respiratory syndromes such as COVID-19, for which progressive respiratory failure is the primary cause of death, and that policy levers to improve air quality may lead to improvements in COVID-19 outcomes.
\end{abstract}

Keywords: Pollution; air quality; PM 2.5; COVID-19; health; mortality JEL: D62; I10; Q53

*We thank Garth Heutel, Julie Hotchkiss, Daniel Kreisman, Rafael Lalive, James Marton, Givi Melkadze, Andrew Schreiber, and Jonathan Smith for very helpful comments on a previous version of this paper. We also thank Unacast, which provided the restricted access data on social distancing. While this paper was completed during his time at Georgia State University, Austin is now affiliated with the National Center for Environmental Economics, U.S. Environmental Protection Agency, Washington, DC. The views expressed in this paper are those of the authors and do not necessarily reflect the views or policies of the U.S. Environmental Protection Agency (EPA). Carattini is also affiliated with CESifo, the London School of Economics and Political Science, and the University of St. Gallen. Carattini acknowledges support from the Grantham Foundation for the Protection of the Environment through the Grantham Research Institute on Climate Change and the Environment and from the ESRC Centre for Climate Change Economics and Policy as well as from the Swiss National Science Foundation, grant number PZ00P1_180006/1. The usual disclaimer applies. 


\section{Introduction}

As of September 2020, the 2019 novel Coronavirus has claimed over 870,000 lives globally. The total number of confirmed Coronavirus cases has soared to 26.3 million. Since the start of the outbreak, unemployment has increased and economic production decreased. Local governments are still defining the best strategies for relaunching economic activity while minimizing the number of additional cases and deaths. A trade-off exists between the speed at which economic activity is reopened and the risk of further cases and deaths.

Our paper expands the policymakers' toolkit by adding one more dimension to this trade-off: contemporaneous air pollution exposure. PM 2.5 has been associated with many of the co-morbidities that relate to poor prognosis and death in COVID-19 patients, including lung and cardiovascular disease. PM 2.5 may therefore contribute to COVID-19 severity, thus increasing demand for testing, due to worsened symptoms, as well as mortality. We show that decreases in contemporaneous pollution are linked to decreases in confirmed COVID-19 cases and mortality. Our empirical approach uses plausibly random daily changes in wind direction to predict air pollution levels, providing quasi-experimental evidence of the effect of PM 2.5 exposure on COVID-19 outcomes (Luechinger, 2014; Deryugina et al., 2019; Anderson, 2020). In our preferred high dimensional fixed effects specification with state-level policy and standard social distancing controls from Unacast cell phone data, we show that a one $\mu \mathrm{g} / \mathrm{m}^{3}$ increase in PM 2.5 increases the number of confirmed cases by roughly $2 \%$ from the mean case rate in a county, where confirmed cases are likely to be a measure for severe cases, given that in the case of COVID-19 many infected people do not show symptoms (Day, 2020; Gandhi et al., 2020; Persico and Johnson, 2020). In absolute terms, this represents 0.7 additional confirmed cases in a county on any given day. In the three-day period following a perturbation in air quality, the relationship between fine particulate matter exposure and cases is over twice as large. Meanwhile, a one $\mu \mathrm{g} / \mathrm{m}^{3}$ increase in PM 2.5 increases the same-day death rate by $3 \%$ from the mean, or between 0.05 and 0.06 additional deaths per 100,000 individuals in a county. These results are in line with the medical literature, which points to progressive respiratory failure as the primary cause of death from COVID-19 (Ackermann et al., 2020), as well as an older literature in economics showing the immediacy of the relationship between exposure to pollution and potential death (see Currie et al., 2014).

Our paper contributes to several strands of literature. To start, we contribute to recent research that associates past exposure to fine particulate matter with COVID-19 mortality (e.g., Wu et al., 2020). Our paper expands our knowledge on the relationship between particulate matter and COVID-19 mortality in two important ways. First, it focuses on current exposure to particulate matter. The contemporaneous dimension is crucial because policymakers have control over current pollution levels but not over past exposure to air pollution. Second, identification relies on plausibly exogenous variation in wind direction à la Deryugina 
et al. (2019), which allows us to causally link particulate matter with COVID-19 outcomes in a nationwide study for the United States, covering virtually all polluting sources. Hence, we generalize previous findings showing that changes in air pollution from recent regulatory changes affecting Toxic Release Inventory sites can have an impact on number of deaths and confirmed cases of COVID-19 (Persico and Johnson, 2020). Further, our study contributes to a growing literature showing detrimental effects of air pollution on a wide range of outcomes, such as infant mortality (e.g., Chay and Greenstone, 2003; Chay et al., 2003; Currie and Neidell, 2005; Knittel et al., 2016), birth weight (e.g., Currie and Walker, 2011), dementia (e.g., Bishop et al., 2018), contemporaneous and long-run education outcomes (e.g., Lavy et al., 2012; Sanders, 2012; Ebenstein et al., 2016) and other measures of productivity (e.g., He et al., 2019). Among the many outcomes that have been studied (see also Currie et al., 2014; EPA, 2019), non-infant mortality has been largely neglected, with only a handful of studies covering it (such as Chay et al., 2003; Chen et al., 2013; Deschênes et al., 2017; Deryugina et al., 2019). Our paper contributes to fill this gap. Further, it adds to the growing body of work illustrating the short-term effect of pollution on health outcomes, including the relationship between days of exposure to pollution and mortality (e.g., Arceo et al., 2016; Simeonova et al., 2018; Deryugina et al., 2019; Anderson, 2020). Overall, we contribute to the literature on pollution and health by showing that air pollution, and in particular fine particulate matter, also plays an important role in the management of deadly infectious diseases such as COVID-19, whose impacts have dramatically affected many cohorts in society, and that these effects emerge very rapidly. Finally, our study contributes to an emerging literature on the economics of the COVID-19 pandemic, aiming at identifying the best possible responses to the current emergency (see Brodeur et al., 2020 for a review). Compared to other studies in the literature, the approach used in this paper has also the advantage of addressing potential measurement error in COVID-19 outcomes.

Our findings have important policy implications. From the contemporaneous relationship between PM 2.5 and COVID-19 morbidity and mortality, it follows that keeping current pollution at low levels may have an immediate payoff in that it may allow for fewer additional cases and deaths when reopening the economy. Policymakers have a wide range of policy levers available to reach this goal, as discussed in Section 6 .

The remainder of the paper is organized as follows. Section 2 describes our data. Section 3 introduces our empirical methods and identification strategy. Section 4 presents our main empirical results. Section 5 confirms these results based on a battery of robustness tests. Section 6 illustrates our main policy implications. Section 7 concludes. 


\section{Data}

This paper uses daily information about the COVID-19 outbreak, pollution levels, wind, and social distancing behavior at the county level from January $22^{\text {nd }}$ to August $15^{\text {th }}$. We also use state-level information on policies adopted to curb the spread of the virus. Our data is limited to the contiguous United States and counties with an EPA air quality monitoring station. In the following sections, we describe data sources and the construction of the final database.

\subsection{Coronavirus Cases and Deaths}

The Johns Hopkins University Center for Systems Science and Engineering provides mortality and caseload information for the study. ${ }^{1}$ It offers a web-based data repository available since January $22^{\text {nd }}$, developed for researchers, public health authorities, and the general public to track the outbreak. The platform reports raw daily caseload and death figures for each county in the United States and has arguably become the standard source of data for cases and deaths in the growing COVID-19 literature. The number of cases and deaths registered in the United States is based on the reports of the Center for Disease Control and Prevention (CDC) and various local health authorities. Summary statistics are presented in the second panel of Table 1, while Figure 1 and Figure 2 present the development of new cases or deaths across the United States over the sample period. The first of these figures represents the pattern of new confirmed cases over the course of the outbreak, illustrating the late March and June waves of contagion in the United States. Figure 2 represents the geographic spread of the disease in each month of the outbreak. In this figure, we depict the total monthly rate of new cases per 100,000 people at the county level from February (Figure 3(a)) to July (Figure $3(\mathrm{f}))^{2}$. Our data reflects the well-known pattern of contagion across the United States, with increasing cases in the Northeast by March and then a spread to new hot spots in the southern and western regions by June.

\subsection{Fine Particulate Matter}

Fine particulate matter or PM 2.5 indicates a combination of particles with diameter of 2.5 micrometers or less, such as nitrates, sulfates, ammonium, and carbon. PM 2.5 found in a given area can be either produced locally or transported from other areas, with transported PM 2.5 being a large share of total PM 2.5. Wind direction is one of the factors influencing transported PM 2.5 (Muller and Mendelsohn, 2007;

\footnotetext{
${ }^{1} 2019$ Novel Coronavirus COVID-19 (2019-nCoV) Data Repository by Johns Hopkins CSSE. https://github.com/CSSEGISandData/COVID-19. Last accessed, September 2, 2020.

${ }^{2}$ In terms of weeks since the first nontravel-related COVID-19 case, Figure 2 panel (a) represents the new cases during the first week of the outbreak, panel (b) new cases during weeks 2 to 5 , (c) weeks 4 to 10 , and weeks 18 to 22 in panel (f).
} 
Deryugina et al., 2019). We source fine particulate information from the EPA's daily outdoor air quality information, AirNow. ${ }^{3}$ Monitoring stations with available data from January to August 2020, and their density by county, are represented in Figure 3. We aggregate monitor air quality information to the countyday level. In counties with more than one monitoring station, air quality data is weighted by the number of people in census blocks in a 10 kilometer buffer around the station. Following Deryugina et al. (2019), the EPA's air quality monitors are classified into 100 clusters based on their location; these clusters are represented in Figure 4. Summary statistics are presented in the first panel of Table 1. Figure 5 maps the mean daily concentration in each month across US counties. We also show the trend in fine particulate matter levels and air quality index over the course of the pandemic in Figure 6. This figure shows that, contrary to media portrayals, air pollution levels have remained generally constant over the course of the pandemic. In addition to PM 2.5 concentrations, AirNow reports Air Quality Index (AQI), which we use as an alternative air quality measurement for robustness analysis.

\subsection{Wind Speed and Direction}

We incorporate information on wind speed and direction from the National Oceanic and Atmospheric Administration's daily weather monitors. ${ }^{4}$ The data includes weather variables for 2,543 weather stations. ${ }^{5}$ Figure 7 presents the spatial distribution and density of weather stations. Weather stations have different reporting frequencies. To address these differences, all reported variables are first aggregated to the stationhour level and then averaged to the station-day level. Among other weather variables, NOAA's stations report information on wind direction and speed. ${ }^{6}$ Wind direction, measured in degrees, is re-coded as suggested by Deryugina et al. (2019) such that the daily mean wind direction is grouped into four categories $\left(1^{\circ}-90^{\circ}, 91^{\circ}-180^{\circ}, 181^{\circ}-270^{\circ}\right.$, and $\left.271^{\circ}-360^{\circ}\right)$. Wind speed is reported in miles-per-hour but is re-coded into ten dummy variables representing deciles of the speed distribution. We consider three strategies in assigning NOAA wind direction information to either EPA air quality monitors or to the county. For our main specifications, each EPA air quality monitor uses a weighted average of the wind direction (in degrees) of the four nearest weather monitors, which approximates a simple Inverse Distance Weighting (IDW) interpolation as employed by Deryugina et al. (2019). ${ }^{7}$ On the other hand, the wind speed data is averaged at the county-day

\footnotetext{
${ }^{3}$ https://www.epa.gov/outdoor-air-quality-data/download-daily-data. Last accessed, September 2, 2020.

${ }^{4}$ https://www.ncei.noaa.gov/data/local-climatological-data/archive/2020.tar.gz. Last accessed, September 2, 2020.

${ }^{5}$ NOAA reports 2,820 monitoring stations between January and August of 2020. After limiting the stations to the contiguous United States, the number reduces to 2,543 .

${ }^{6}$ The data also includes information on weather conditions such as precipitation and temperature. Because these variables are frequently missing, we do not include them as controls in our analysis.

${ }^{7}$ Therefore, the assigned wind direction for EPA station $i$ at time $t\left(D I R_{i t}\right)$ is given by $D I R_{i t}=\frac{\sum_{j=1}^{4} w_{j} D I R_{j t}}{\sum_{j=1}^{4} w_{j}}$, where $D I R_{j t}$ is the wind direction of the $j^{t h}$ nearest weather monitor at time $t$, and $w_{j}=\left(d_{i j}\right)^{-1}$ is the weight of the $j^{t h}$ monitor based on the distance between $i$ and $j\left(d_{i j}\right)$.
} 
level. We explore the sensitivity of our results to this wind-to-air quality assignment mechanism in Section 5 and more specifically Table A6 and Table A7.

\subsection{Social Distancing Metrics}

The data company Unacast creates social distancing records by county using cell phone information (Unacast, 2020). ${ }^{8}$ We use three relevant variables created by Unacast: change to average daily distance traveled from pre-COVID baseline, change to average daily visits to non-essential locations from pre-COVID baseline, and change to average daily encounters per square kilometer from baseline. Change to average distance traveled is a z-score difference in mean distance traveled for all cell phones in a county from the average traveled distance on the same weekday in a pre-COVID period (March $8^{\text {th }}$ or earlier). The second indicator, change to average daily visits, controls for essential movements by distinguishing between essential and non-essential facilities. ${ }^{9}$ As with change to average distance traveled, changes to visitations are reported as z-scores. Finally, the rate of encounters captures person-to-person contact. Since Unacast's underlying cell phone data do not identify if two people have met, they define person-to-person contact as each time two users are within 50 meters of each other for 60 minutes or less. This value is then normalized by the counties' area (in square kilometers) and compared to a national baseline defined as the average encounters for a pre-outbreak period (February $10^{\text {th }}$ to March $8^{\text {th }}$ ). ${ }^{10}$ In all regression specifications, we use the average of all daily values from the previous 2-week period as control variables. Summary statistics are presented in Table 1.

\subsection{State-Level Policy Adoption}

We use the COVID-19 Government Response Event Dataset (CoronaNet v1.0) via Safegraph to control for adoption of aversive policy behavior by state governments (Cheng et al., 2020). ${ }^{11}$ The full list of policies includes limiting mass gatherings, social distancing actions, stay at home or quarantine orders, school closures, testing initiatives, state border closures, public surface cleaning, curfews, information campaigns, state of emergency declarations, administrative task forces, policies to provide greater access to personal protective equipment, and other policies to increase access to healthcare resources (such as respirators). For each county, we create indicator variables equal to one if the policy has started and has not yet ended. Summary statistics are presented in Table 1.

\footnotetext{
${ }^{8}$ See https://www.unacast.com/. Last accessed, September 2, 2020.

${ }^{9}$ Unacast categorized "essential" based on states' guidelines. Essential locations include facilities like food stores, pet stores, and pharmacies, while non-essential facilities include restaurants, department and clothing stores, spas and hair salons between others. See https://www.unacast.com/post/unacast-updates-social-distancing-scoreboard for more detail on Unacast's methodology. Last accessed, September 2, 2020

${ }^{10}$ For more detail on the indicator's origin and the methodology followed by Unacast, see https://www.unacast.com/post/rounding-out-the-social-distancing-scoreboard. Last accessed, September 2, 2020

${ }^{11}$ https://www.coronanet-project.org/download.html. Last accessed, September 2, 2020.
} 


\section{Methods}

We follow Deryugina et al. (2019) in instrumenting for air pollution with local wind direction, with the aim of identifying the effect of acute exposure to air pollution on our outcomes of interest. Let $P M 2.5_{\text {iswt }}$ represent the average PM 2.5 concentration in county $i$, state $s$, week of the outbreak $w$, and day $t$. $y_{i s w t}$ is the health outcome of interest; these outcomes include the daily rate of confirmed COVID-19 cases per 100,000 population, the raw daily count of COVID-19 cases, the rate of confirmed COVID-19 deaths per 100,000 population, and the raw daily count of COVID-19 deaths. We also explore the same case and death outcomes over 3-day, 7-day, 10-day, and 14-day periods. Consider the following two stage least squares regression equation:

$$
\begin{gathered}
P M 2.5_{i s w t}=\sum_{g \in G} \sum_{b=0} \beta_{b}^{g} 1\left[G_{i}=g\right] * D I R_{i t}^{90 b}+X^{\prime} \gamma+\eta_{i}+\eta_{s w}+\nu_{i s w t} \\
y_{\text {iswt }}=\phi P M 2.5_{i s w t}+X^{\prime} \gamma+\eta_{i}+\eta_{\text {sw }}+\epsilon_{\text {iswt }}
\end{gathered}
$$

In Equation 1, $D I R_{i t}$ represents four wind direction dummies indicating whether average wind direction falls into one of four $90^{\circ}$ quadrants for county $i$ on day $t .^{12}$ As in Deryugina et al. (2019), variable $1\left[G_{i}=g\right]$ is an indicator function asserting that county $i$ belongs to wind monitor group $g$ in the set of all wind monitor clusters $G$. Our excluded instruments are the full interaction of wind monitor clusters with wind direction dummies, or 382 interaction terms. Intuitively, the $\beta$ coefficients capture how a wind direction and locality combination influences average PM 2.5 levels in a county on the same day. ${ }^{13}$ Aside from the excluded instruments, Equation 1 includes the term $X$ for a suite of time-varying controls for state-level COVID-19 mitigation policies, day of the week, nine county-level dummies for wind speed categories, two lagged wind direction-by-cluster variables, and prior 2-week averages of Unacast social distancing metrics based on cell phone data. Unacast social distancing variables are the change in average distance traveled from county-level baseline, change in visits from baseline, and change in the rate of human encounters per square kilometer. We incorporate lagged 2-week averages for these variables to control for behavior over the relevant incubatory period of COVID-19. ${ }^{14} \epsilon_{i s t w}$ is a random error term clustered at the county level. The

\footnotetext{
${ }^{12}$ We omit the wind direction dummy representing $271^{\circ}-360^{\circ}$.

${ }^{13}$ For example, a wind direction is allowed to influence air pollution in the Chesapeake Bay region differently than the same wind direction in the San Francisco bay region.

${ }^{14}$ We note that social distancing behavior over the previous two-week period may potentially be correlated with air quality. We take this theoretical possibility seriously and test the sensitivity of our results to alternative specifications in which we alter the control variables in our model, as shown in Table A2 and Table A3. We further discuss this potential issue in Section 5 .
} 
coefficient of interest in Equation 1 is $\phi$, an estimate of the relationship between an additional $\mu \mathrm{g} / \mathrm{m}^{3}$ of PM 2.5 and cases or deaths from COVID-19.

Equation 1 incorporates county and state-by-week fixed effects, $\eta_{i}$ and $\eta_{s w} \cdot{ }^{15}$ These fixed effects control for time-constant county-level heterogeneity and time-varying state-level characteristics. ${ }^{16}$ Due to the nature of the spread of a contagion, the state-by-week fixed effects are best suited for controlling for the evolving baseline infection rate in a local population, endogenous responses to the infection rate, and the ways in which underlying heterogeneity may interact with these dynamics. Intuitively, these fixed effects allow us to ask how better or worse air quality impacts the severity of the COVID-19 outbreak while taking a ceteris paribus approach with respect to local characteristics, infection rate, and behaviors. For the purpose of comparison, we also show results with county and metropolitan statistical area-by-week or combined statistical area-by-week fixed effects specifications. ${ }^{17}$

In line with Deryugina et al. (2019), the identifying assumption is that, after flexibly controlling for the above-mentioned variables, county-level variation in daily wind direction is unrelated to variation in morbidity and mortality in the same county, if not through variation in air pollution. Hence, this empirical approach provides quasi-experimental evidence of the effect of air pollution, instrumented by changes in wind direction, on health outcomes, while addressing common issues identified in the literature, including measurement error from various sources.

\section{Results}

\subsection{COVID-19 Cases}

Contemporaneous exposure to air pollution may influence the severity of illness, thereby increasing the number of severe cases. Table 2 shows our primary results on confirmed cases across a range of fixed effects specifications. In columns (1) through (3), we show the relationship between PM 2.5 and case rates per 100,000 individuals in a county. Columns (4) through (6) regress wind-fitted PM 2.5 on case totals. In column (1), we find that an increase of one $\mu \mathrm{g} / \mathrm{m}^{3}$ of fine particulate matter in a county will increase the

\footnotetext{
${ }^{15}$ To this end, we use the Stata command ivreghdfe (Correia, 2016).

${ }^{16}$ The use of state-by-week fixed effects, or within-week comparisons, imply that we are not investigating how air quality affects the speed of transmission of the virus but rather how air quality affects the severity of illness among already-infected individuals. Confirmed cases are expected to represent more severe cases, for which infected individuals experience symptoms and seek testing (Day, 2020; Gandhi et al., 2020). We do not expect air pollution to change the threshold of pain and symptoms leading individuals to seek testing, but rather to increase the number of people whose pain and symptoms exceed such threshold. We also note that identifying the speed of transmission is beyond the scope of our paper. The often-lengthy incubation period, testing lags, and reporting lags mean that our estimation procedure does not identify the speed of transmission.

${ }^{17}$ In each of these specifications, counties that are not in an MSA or CBSA are assigned state-by-week fixed effects. For example, a county and MSA-by-week fixed effects specification would make within-MSA, within-week comparisons for MSAs, while rural regions would be compared to other non-MSA regions in the same state and week. To avoid over-fitting, any MSA or CBSA with only one county is also assigned the state-by-week fixed effect.
} 
number of confirmed cases per 100,000 population by 0.13 . This is roughly a $2 \%$ increase from the mean case rate per county on a given day. In columns (2) and (3), we show that this increase is roughly constant at 0.12 and 0.11 when adopting MSA-by-week or CBSA-by-week fixed effects. In our regressions on total cases in columns (4) through (6), a one unit increase of PM 2.5 in a county results in 4-5 additional cases within a county on the same day. These estimates reflect larger percent changes from the mean than those observed on case rates, and they are consistent across fixed effects specifications. However, our point estimates are less-precisely estimated in regressions on case totals.

We quantify the magnitude of these findings in two ways. First, the within-county standard deviation of average daily PM 2.5 over our sample period is $3.6 \mu \mathrm{g} / \mathrm{m}^{3}$. Therefore, a wind-induced shift in PM 2.5 of one standard deviation would be expected to increase cases in any given county by at least $6 \%$ from the mean. Second, we estimate the approximate change over the support of wind-induced PM 2.5 shifts. We incorporate four wind-direction dummies. Within any county, the wind direction associated with lowest PM 2.5 levels has an average PM 2.5 level of $4.9 \mu \mathrm{g} / \mathrm{m}^{3}$; the second is 5.9 , third is 6.9 , and the highest wind direction is associated with mean PM 2.5 level of $7.9 \mu \mathrm{g} / \mathrm{m}^{3}$. These categories illustrate that any given county has wide variation in PM 2.5 levels associated with wind direction, ranging an average of $3 \mu \mathrm{g} / \mathrm{m}^{3}$ from lowest to highest wind direction-pollution combination. Therefore, any given county would be expected to see at least $5 \%$ more confirmed cases on the worst wind-pollution combination days in comparison to the best ones, or at least a $1.7 \%$ increase in confirmed cases from even a slight step up in PM 2.5 associated with a marginal change in wind direction. For comparison, Persico and Johnson (2020) found that a one unit increase in fine particulate matter led to an approximate doubling of confirmed cases and deaths. Recall that the effects in Persico and Johnson (2020) are induced by regulatory rollback of pollution control at Toxic Release Inventory sites. Because these sites release many harmful pollutants other than fine particulate matter, it seems reasonable that the magnitude of their findings would be higher than those we observe. Further, populations especially exposed to pollution from Toxic Release Inventory sites may be more vulnerable for a variety of reasons, including past exposure to the many harmful pollutants released at those sites. Persico and Johnson (2020) analyze heterogeneous effects along standard socioeconomic dimensions and find worse pollution exposure for counties with a higher fraction of Black individuals, with higher unemployment, and with lower incomes. Our approach allows isolating the effect of PM 2.5 while inferring from a much broader set of pollution sources, thus generalizing previous results. A wide set of policy implications follow from our empirical findings, which we discuss in Section 6.

Further, we show how air pollution impacts the number of cases over the following $3,7,10$, and 14 day periods in Table 4. For concision, we show only specifications with county and state-by-week fixed effects. ${ }^{18}$

\footnotetext{
${ }^{18}$ All additional estimations are available by the authors upon request.
} 
In column (1), we see our previous result that a one $\mu \mathrm{g} / \mathrm{m}^{3}$ increase in PM 2.5 increases the case rate by 0.13 and the total cases by 5.4 on the same day. Column (2) of the table suggests that a one unit increase in fine particulate matter in a given county is expected to increase the number of cases per 100,000 by 0.3 over the following three day period. While this effect in magnitude is over twice as large, it is a smaller percent increase relative to the mean 3 -day combined case rate at $1.5 \%$. Meanwhile, the same one unit increase would be expected to increase the case rate by 0.17 over a seven day period, 0.37 over a ten-day period and by 0.43 over a two week period. It seems reasonable that the magnitude of the findings would increase over longer time horizons, as a given exposure to pollution may lead the severity of cases to increase over several days, and testing or reporting lags may further delay the time of confirmation. At the same time, our estimates tend to become noisier over longer time horizons. In the second panel of Table 4, we observe a similar increasing relationship between PM 2.5 and confirmed cases when our outcome is total cases. The relationship between a one unit increase in PM 2.5 and confirmed cases over three days is 23, four times higher than the magnitude of our same-day estimations. Over two weeks, the relationship increases to 111 additional confirmed cases per unit of PM 2.5, or a $22 \%$ increase from the mean 2-week case total.

\subsection{COVID-19 Deaths}

Table 3 displays point estimates for the relationship between levels of fine particulate matter and confirmed COVID-19 deaths. As in Table 2, columns (1) through (3) display results on death rates per 100,000 individuals, while columns (4) through (6) show the relationship between PM 2.5 and death totals. The point estimate in column (1) suggests that an additional unit of wind-induced PM 2.5 would raise the sameday death rate from COVID-19 by 0.006 . This is a $3 \%$ increase from the mean daily death rate within a county of 0.18. This coefficient is generally stable when adopting MSA-by-week or CBSA-by-week fixed effects in place of the state-by-week fixed effects, as displayed in column (2) and column (3). Meanwhile, our estimates in columns (4) through (6) suggest that a one-unit increase in PM 2.5 would increase the absolute death count by $0.07-0.09$, or roughly a $7 \%$ increase from the mean number of COVID-19 deaths in a county on any given day. For comparison, the cross-sectional estimates in Wu et al. (2020) suggest, if taken at face value, that a $\mu \mathrm{g} / \mathrm{m}^{3}$ increase in average historical exposure to PM 2.5 is associated with an $8 \%$ increase in the rate of deaths from COVID-19.

Finally, consistent with Deryugina et al. (2019), we examine the relationship between exposure to an additional unit of PM 2.5 and COVID-19 deaths over longer time horizons. The corresponding estimates are provided in Table 5. For death rates, we show that the relationship remains roughly constant at 0.006 for up to three days, but then we observe no discernible relationship between exposure to PM 2.5 and death rates 
over 7, 10, and 14 day periods. Conversely, we observe a slightly increasing relationship between exposure to PM 2.5 and death totals over up to two week periods, with a single unit of PM 2.5 exposure increasing two-week death counts by approximately 2 individuals per county, an $11 \%$ increase from the mean two-week county death rate of 17 . Our results suggest that a county would have $33 \%$ fewer deaths if wind came from the least-polluted direction for two weeks, in comparison to itself if wind came from the most-polluted direction for two weeks.

\section{Robustness Tests}

In this section, we assess the sensitivity of our results to a battery of alternative specifications. We proceed as follows. First, we re-examine our relationship of interest when replacing PM 2.5 with EPA's Air Quality Index as independent variable. Second, we test the sensitivity of our results to inclusion of different timevarying daily controls. In particular, we show how our results compare when dropping social distancing metrics. Third, we drop New York City, which may be considered a special case in the context of the COVID-19 epidemic. Fourth, we compare our instrumental variable approach to estimations using Ordinary Least Squares. Fifth, we explore alternate mechanisms for assigning wind and weather information to air quality monitors.

AQI vs. PM 2.5: We use PM 2.5 as our primary independent variable to represent air pollution, although a variety of air pollutants contribute to air quality. We therefore also test our primary regression specification with EPA's Air Quality Index (AQI) as the independent variable. As with PM 2.5, we construct this variable by population-density weighting AQI measures when more than one monitor is present in a county. The results are presented in Table A1. In all regression specifications, the relationship between AQI and COVID19 morbidity and mortality is of the same sign and similar statistical significance as the relationship between PM 2.5 and COVID-19 morbidity and mortality. For case rates, the relationship is actually much more precisely estimated across all fixed effects specifications, although death rate point estimates have slightly less statistical significance. The magnitude of the point estimates, however, are consistent across PM 2.5 and AQI if not slightly larger for AQI. For example, we see that a one unit increase in AQI in a county would lead to a $0.6 \%$ increase in case and a $0.8 \%$ increase in death rates. Scaling these by the mean AQI, which is four times as large as the mean PM 2.5, results in similar shifts from PM 2.5 in the range of $2 \%$ and $3 \%$, respectively. The fact that the magnitude is of similar range, if not slightly larger, makes sense, as fine particulate matter is not the only harmful air pollutant that may exacerbate COVID-19 outcomes. 
Inclusion of Different Time-Varying Controls: Our primary regressions control for state-level policies to control the spread of COVID-19, wind speed dummies, past 2-week average social distancing information, day of the week, and two days of lagged wind-direction combinations. In Table A2, we show how our primary results differ when subsets of controls are used. In columns (1) and (5), we show how our results differ when no controls are adopted except lagged wind-direction combination. Coefficients for case rates and counts, as well as death rates and counts, are all less-precisely estimated. Point estimates for case or death rates are half as large as our primary estimates, although estimates for case or death totals are similar, even slightly larger, than our primary estimates. When adding day of week and wind speed dummies, our results for case and death rates are larger and more precisely-estimated, achieving statistical significance for case rates and near significance for death rates. Incorporating either state-level policies or social distancing controls, in columns (3), (4), (7), and (8), very slightly improves the precision of our estimates in most specifications. However, the magnitude of the point estimates remains roughly constant across all specifications. If anything, this evidence compounds that provided in Deryugina et al. (2019) on the validity of wind direction as an instrument for air pollution.

With respect to case rates and death rates, inclusion of past 2-week average social distancing controls slightly elevates our point estimates, while case counts and death counts appear unaffected. In Table A3, we test how our primary results differ when excluding all past 2-week average social distancing metrics. Point estimates are similar in all models, although we note that slight attenuation does occur in most specifications. Hence, we conclude that our approach is able to capture the main effect of interest, even if past 2-week average social distancing behavior may be correlated with pollution through two channels, avoidance behavior (Graff Zivin and Neidell, 2009; Neidell, 2009; Deschênes et al., 2017) and the fact that past social distancing behavior may generate less pollution.

Drop New York City: The first major outbreak of COVID-19 in the continental United States occurred in the metropolitan region surrounding New York City, a large and heavily-populated zone with unique characteristics with respect to its outbreak intensity, COVID-19 response, and pollution levels. In Table A4, we test whether our results differ when excluding this region from the sample. ${ }^{19}$ In virtually all specifications, our results are larger in magnitude and more precisely estimated when excluding New York City. With the exception of death counts, we observe highly statistically significant relationships between an additional unit of PM 2.5 and each outcome. For example, in column (1), we observe that an additional unit of PM 2.5 increases case rates per 100,000 individuals by 0.15 , a $2.4 \%$ increase. In comparison, our estimations including New York City showed an increase of 0.13 cases, or a $2 \%$ increase. The increase in case counts is

\footnotetext{
${ }^{19}$ We exclude the counties or boroughs of Nassau, Westchester, Queens, Manhattan, Brooklyn, and the Bronx. Corresponding FIPS codes for these regions are 36059, 36119, 36081, 36061, 36047, and 36005.
} 
now 6-7 additional confirmed COVID-19 cases per unit of PM 2.5. Though still statistically insignificant, these point estimates are more precisely estimated than our results including New York City. Meanwhile, the increase in the death rate, now highly significant, is 0.009 instead of 0.006 per 100,000 individuals, a $5 \%$ increase instead of a $3 \%$ increase. Regressions on total deaths, previously a statistically insignificant 0.08 or $7 \%$ per additional unit of PM 2.5, are now a sizeable and statistically significant 0.3 , a $34 \%$ from the mean daily death count. From these results, we conclude that our findings are robust to the exclusion of the New York City region.

Instrumental Variables vs. Ordinary Least Squares: The previous literature has identified measurement error as one of the main issues when analyzing the effect of air pollution on health outcomes, thus leading to the use of an instrumental variable approach to overcome it (Deryugina et al., 2019). This approach can also tackle other non-random sources of variation in the pollution-health relationship, which also limit the extent to which naive estimations via Ordinary Least Squares may lead to causal estimates. As per standard procedure, we compare estimates obtained with the instrumental variable approach to estimates obtained via Ordinary Least Squares to ascertain the direction and magnitude of the bias, if any. In Table A5, we show the reduced-form relationship between concentrations of fine particulate matter and confirmed cases and deaths on the same day, using Ordinary Least Squares. We estimate these relationships across the same fixed effects as before. In the first panel and first column of Table A5, we see that an additional unit of PM 2.5 is associated with a 0.03 increase in the case rate per 100,000 population. This is a $0.4 \%$ increase relative to the mean daily case rate in a county. Similarly, in column (4) we see that a one unit increase in PM 2.5 is associated with 6 additional confirmed cases in a county. While these coefficients are of the same sign as our baseline point estimates, they are less precisely estimated. In the case of case rates, they are also much smaller in magnitude, reflecting a $0.4 \%$ change from an additional unit of PM 2.5 instead of a $2 \%$ shift. Ordinary Least Squares coefficients are essentially zero for all regressions on death rates; for death counts, the coefficients are of the same sign as our instrumental variable point estimates but one tenth the magnitude. The standard errors are also approximately four times as large as the coefficient. For comparison, our instrumental variable estimates suggest an additional unit of PM 2.5 raises the daily death count by 0.08 , while the Ordinary Least Squares estimate is 0.008 . Hence, our comparison of estimates between our main specifications and Ordinary Least Squares tends to confirm the conclusion of Deryugina et al. (2019) on the influence of measurement error in naive regressions.

Matching Weather Stations to Air Quality Monitors: We assign wind direction variables to air quality monitors by inverse-distance weighting wind direction values of the four nearest weather stations. 
This assignment mechanism approximates that of Deryugina et al. (2019), in which a complete national wind direction and speed interpolation allows flexible assignment of wind variables to any given air quality monitor location. ${ }^{20}$ We also present results under two alternative assignment mechanisms. First, we assign wind direction based on only the closest weather station. ${ }^{21}$ Next, we assign wind direction based on inverse-distance weighting wind direction values of the twelve nearest weather stations. We present our main empirical specifications with these alternate wind direction assignments in Table A6 and Table A7. When assigning wind direction based on only the closest weather station, our results on cases are virtually unchanged. However, we note slight attenuation in our point estimates on death rates as well as imprecise estimates on death totals. Meanwhile, when assigning wind direction based on the twelve nearest weather stations, all coefficients are very similar to our baseline estimations, with all coefficients in regressions on death rates or counts are of larger magnitude. These results suggest that use of a single weather station to assign wind direction may noisily capture weather patterns in the surrounding region, while our estimates are robust to averaging wind direction over up to twelve nearest weather stations.

\section{Policy Relevance}

Our findings indicate that higher contemporaneous exposure to PM 2.5 leads to higher COVID-19 morbidity and mortality. While concentrations of PM 2.5 may have decreased in some cities across the United States in the early days of the COVID-19 outbreak (see Berman and Ebisu, 2020), we observe little change in PM 2.5 or AQI levels nationwide over the course of the pandemic. Further, Persico and Johnson (2020) report an increase in particulate matter in counties with TRI sites since the pandemic began, suggesting that environmental deregulation may have largely offset any decrease in air pollution driven by less motorized traffic. Figure 6 shows a pattern consistent with these elements. Meanwhile, the overall number of COVID19 cases and deaths has continued to increase in the United States as well as globally. It follows from our findings that there is a continued rationale for limiting pollution levels while reopening the economy. In this section, we discuss several policy levers that may be used by policymakers at the federal, state, and local level. Private companies may also contribute to keep current pollution down as part of their corporate social responsibility strategies by letting employees telework whenever appropriate. As suggested in Persico and Johnson (2020), hospitals may consider using air purifiers in rooms with COVID-19 patients, to limit exposure to air pollution and prevent the need for ventilators.

At the federal level, reinstating air pollution control and reporting regulations, requirements lifted in

\footnotetext{
${ }^{20}$ Deryugina et al. (2019) use the North American Regional Reanalysis (NARR) daily reanalysis data. Since our study uses contemporaneous wind and air quality information, NARR data is not yet readily available for our sample time period.

${ }^{21}$ If the nearest weather station is missing wind information for a given day, we assign wind variables based on the secondclosest weather station.
} 
March 2020, may lower releases by large polluting sites and thereby improve COVID-19 morbidity and mortality outcomes. Additional immediate policy levers may emerge in case of a new recovery package, which could complement the Coronavirus Aid, Relief, and Economic Security (CARES) Act of March $27^{\text {th }}$ 2020. Relief funds could, for instance, be provided to some industries conditional on pollution reductions. Airlines are a case in point. The CARES Act required airline companies to maintain a minimum number of flights between destinations that were served before the outbreak started. Many of those flights are likely to be carried out at very low levels of capacity, thus generating pollution at the same time that they create operational losses to the airlines. Renegotiating the terms of the agreement in the light of our findings may be in the interest of both society and the airlines.

State regulations can limit the extent with which people can move for non-essential activities and encourage continued teleworking as much as possible, in case voluntary efforts by companies are deemed insufficient. Local governments can also regulate traffic and pollution directly. For instance, adjusting speed limits on highways to current traffic conditions can reduce pollution (Bel and Rosell, 2013). Temporary policies using alternate license plates can be enforced for non-essential movements, for instance allowing individuals with an even final digit on the license plate number to circulate only on even days of the month (Davis, 2008; Gallego et al., 2013; Li, 2018). Retrofitted public transit vehicles can be used whenever possible (Beatty and Shimshack, 2011; Austin et al., 2019), especially as long as the number of routes and the frequency of service have both been adjusted downward during the outbreak. To the extent that it is feasible in the short run, expanding current public transit infrastructure would also contribute to limit local air pollution (Lalive et al., 2018; Li et al., 2019). Expanding subsidies for electric and hybrid vehicles as well as charging stations may also accelerate the transition to cleaner vehicles (Beresteanu and Li, 2011; Li et al., 2017; Muehlegger and Rapson, 2018), depending on the local context (Holland et al., 2016), the expected duration of the current pandemic (Scudellari, 2020), as well as expectations about future ones.

Many of these policy implications apply also to other countries in the world. Further, all cities with congestion charges already in place, such as Gothenburg, London, Milan, Singapore, or Stockholm, may consider adjusting the price level to reflect current pollution levels and the spread of COVID-19 (Coria et al., 2015). Congestion charges have indeed been shown to reduce overall traffic and pollution (Leape, 2006; Gibson and Carnovale, 2015). Several cities around the world also limit access to city centers or entire regions to some vehicles, depending on vintage, fuel type, and efficiency (e.g., Barahona et al., 2019). Such regulations may also be adjusted during the pandemic. Over the longer run, COVID-19-related deaths could be used as an additional impetus to internalize known externalities from local air pollution (e.g. Parry and Small, 2005; Muller and Mendelsohn, 2009). 


\section{Conclusion}

The novel Coronavirus has caused hundreds of thousands of deaths and severe economic damage across the world. The common experience of many countries has shown that a trade-off exists between the speed at which economic activity is relaunched and the risk of further cases and deaths. This trade-off is usually described as between two important but conflicting goals: jobs and economic recovery on one side, and limiting cases and deaths on the other. Our paper adds one dimension to this trade-off, pointing to an untapped potential to limit severe cases and deaths while sustaining economic recovery. Our study shows that the observed trade-off between the two aforementioned desirable goals can be relaxed by keeping current pollution at low levels. Indeed, we find strong evidence that current air quality almost immediately affects the severity of COVID-19 illness. According to our results, a one $\mu \mathrm{g} / \mathrm{m}^{3}$ increase in PM 2.5 (about $15 \%$ of the average concentration of PM 2.5) increases the number of severe cases by roughly $2 \%$ and same-day deaths by $3 \%$ from the mean case rate in a county. Our results rely on arguably exogenous variation in wind direction and are robust to a wide variety of specifications. Overall, our study points to a potentially important role for policy levers aimed at lowering pollution in addressing the pandemic. 


\section{References}

Ackermann, M., S. E. Verleden, M. Kuehnel, A. Haverich, T. Welte, F. Laenger, A. Vanstapel, C. Werlein, H. Stark, A. Tzankov, W. W. Li, V. W. Li, S. J. Mentzer, and D. Jonigk (2020). Pulmonary vascular endothelialitis, thrombosis, and angiogenesis in Covid-19. New England Journal of Medicine 383(2), $120-128$.

Anderson, M. L. (2020). As the wind blows: The effects of long-term exposure to air pollution on mortality. Journal of the European Economic Association 18(4), 1886-1927.

Arceo, E., R. Hanna, and P. Oliva (2016). Does the effect of pollution on infant mortality differ between developing and developed countries? Evidence from Mexico City. The Economic Journal 126(591), 257280 .

Austin, W., G. Heutel, and D. Kreisman (2019). School bus emissions, student health and academic performance. Economics of Education Review 70, 109-126.

Barahona, N., F. A. Gallego, and J.-P. Montero (2019). Vintage-specific driving restrictions. The Review of Economic Studies 87(4), 1646-1682.

Beatty, T. K. M. and J. P. Shimshack (2011). School buses, diesel emissions, and respiratory health. Journal of Health Economics 30(5), 987-999.

Bel, G. and J. Rosell (2013). Effects of the $80 \mathrm{~km} / \mathrm{h}$ and variable speed limits on air pollution in the metropolitan area of Barcelona. Transportation Research Part D: Transport and Environment 23, 90-97.

Beresteanu, A. and S. Li (2011). Gasoline prices, government support, and the demand for hybrid vehicles in the United States. International Economic Review 52(1), 161-182.

Berman, J. D. and K. Ebisu (2020). Changes in u.s. air pollution during the covid-19 pandemic. Science of The Total Environment 739, 139864.

Bishop, K. C., J. D. Ketcham, and N. V. Kuminoff (2018). Hazed and confused: The effect of air pollution on dementia. Report 0898-2937, National Bureau of Economic Research.

Brodeur, A., D. M. Gray, A. Islam, and S. Bhuiyan (2020). A literature review of the economics of Covid-19. SSRN Scholarly Paper ID 3636640, Social Science Research Network, Rochester, NY.

Chay, K., C. Dobkin, and M. Greenstone (2003). The Clean Air Act of 1970 and adult mortality. Journal of Risk and Uncertainty 27(3), 279-300.

Chay, K. and M. Greenstone (2003). The impact of air pollution on infant mortality: Evidence from geographic variation in pollution shocks induced by a recession. The Quarterly Journal of Economics 118(3), $1121-1167$.

Chen, Y., A. Ebenstein, M. Greenstone, and H. Li (2013). Evidence on the impact of sustained exposure to air pollution on life expectancy from China's Huai River policy. Proceedings of the National Academy of Sciences of the United States of America 110(32), 12936-12941.

Cheng, C., J. Barceló, A. Hartnett, R. Kubinec, and L. Messerschmidt (2020). Covid-19 government response event dataset (coronanet v1.0).

Coria, J., J. Bonilla, M. Grundström, and H. Pleijel (2015). Air pollution dynamics and the need for temporally differentiated road pricing. Transportation Research Part A: Policy and Practice 75, 178-195.

Correia, S. (2016). Linear models with high-dimensional fixed effects: An efficient and feasible estimator. Working Paper.

Currie, J. and M. Neidell (2005). Air pollution and infant health: What can we learn from California's recent experience? The Quarterly Journal of Economics 120(3), 1003-1030. 
Currie, J. and R. Walker (2011). Traffic congestion and infant health: Evidence from E-ZPass. American Economic Journal: Applied Economics 3(1), 65-90.

Currie, J., J. G. Zivin, J. Mullins, and M. Neidell (2014). What do we know about short- and long-term effects of early-life exposure to pollution? Annual Review of Resource Economics 6(1), 217-247.

Davis, L. W. (2008). The effect of driving restrictions on air quality in Mexico City. Journal of Political Economy 116(1), 38-81.

Day, M. (2020). Covid-19: Four fifths of cases are asymptomatic, China figures indicate. BMJ 369.

Deryugina, T., G. Heutel, N. H. Miller, D. Molitor, and J. Reif (2019). The mortality and medical costs of air pollution: Evidence from changes in wind direction. American Economic Review 109(12), 4178-4219.

Deschênes, O., M. Greenstone, and J. S. Shapiro (2017). Defensive investments and the demand for air quality: Evidence from the NOx Budget Program. American Economic Review 107(10), 2958-2989.

Ebenstein, A., L. Victor, and R. Sefi (2016). The long-run economic consequences of high-stakes examinations: Evidence from transitory variation in pollution. American Economic Journal: Applied Economics 8(4).

EPA (2019). Integrated science assessment (ISA) for particulate matter. Technical Report EPA/600/R19/188, U.S. Environmental Protection Agency, Washington, DC.

Gallego, F., J.-P. Montero, and C. Salas (2013). The effect of transport policies on car use: Evidence from Latin American cities. Journal of Public Economics 107, 47-62.

Gandhi, M., D. S. Yokoe, and D. V. Havlir (2020). Asymptomatic transmission, the Achilles' heel of current strategies to control Covid-19. New England Journal of Medicine 382(22), 2158-2160.

Gibson, M. and M. Carnovale (2015). The effects of road pricing on driver behavior and air pollution. Journal of Urban Economics 89, 62-73.

Graff Zivin, J. and M. Neidell (2009). Days of haze: Environmental information disclosure and intertemporal avoidance behavior. Journal of Environmental Economics and Management 58(2), 119-128.

He, J., H. Liu, and A. Salvo (2019). Severe air pollution and labor productivity: Evidence from industrial towns in China. American Economic Journal: Applied Economics 11(1), 173-201.

Holland, S. P., E. T. Mansur, N. Z. Muller, and A. J. Yates (2016). Are there environmental benefits from driving electric vehicles? The importance of local factors. American Economic Review 106 (12), 3700-3729.

Knittel, C. R., D. L. Miller, and N. J. Sanders (2016). Caution, drivers! children present: Traffic, pollution, and infant health. The Review of Economics and Statistics 98(2), 350-366.

Lalive, R., S. Luechinger, and A. Schmutzler (2018). Does expanding regional train service reduce air pollution? Journal of Environmental Economics and Management 92, 744-764.

Lavy, V., A. Ebenstein, and S. Roth (2012). The impact of air pollution on cognitive performance and human capital formation.

Leape, J. (2006). The London Congestion Charge. Journal of Economic Perspectives 20(4), 157-176.

Li, S. (2018). Better lucky than rich? Welfare analysis of automobile licence allocations in Beijing and Shanghai. The Review of Economic Studies 85(4), 2389-2428.

Li, S., Y. Liu, A.-O. Purevjav, and L. Yang (2019). Does subway expansion improve air quality? Journal of Environmental Economics and Management 96, 213-235.

Li, S., L. Tong, J. Xing, and Y. Zhou (2017). The market for electric vehicles: Indirect network effects and policy design. Journal of the Association of Environmental and Resource Economists 4(1), 89-133. 
Luechinger, S. (2014). Air pollution and infant mortality: A natural experiment from power plant desulfurization. Journal of Health Economics 37, 219-231.

Muehlegger, E. and D. S. Rapson (2018). Subsidizing mass adoption of electric vehicles: Quasi-experimental evidence from California. Working Paper 25359, National Bureau of Economic Research.

Muller, N. Z. and R. Mendelsohn (2007). Measuring the damages of air pollution in the United States. Journal of Environmental Economics and Management 54(1), 1-14.

Muller, N. Z. and R. Mendelsohn (2009). Efficient pollution regulation: Getting the prices right. American Economic Review 99(5), 1714-1739.

Neidell, M. (2009). Information, avoidance behavior, and health: The effect of ozone on asthma hospitalizations. Journal of Human Resources 44 (2), 450-478.

Parry, I. W. H. and K. A. Small (2005). Does Britain or the United States have the right gasoline tax? American Economic Review 95(4), 1276-1289.

Persico, C. and K. R. Johnson (2020). Deregulation in a time of pandemic: Does pollution increase coronavirus cases or deaths? (13231).

Sanders, N. J. (2012). What doesn't kill you makes you weaker: Prenatal pollution exposure and educational outcomes. Journal of Human Resources 47(3), 826-850.

Scudellari, M. (2020). How the pandemic might play out in 2021 and beyond. Nature 584(7819), 22-25.

Simeonova, E., J. Currie, P. Nilsson, and R. Walker (2018). Congestion pricing, air pollution and children's health. Working Paper 24410, National Bureau of Economic Research. Series: Working Paper Series.

Unacast (2020). Unacast social distancing dataset. https://www.unacast.com/data-for-good. Version from 17 April 2020.

Wu, X., R. C. Nethery, B. M. Sabath, D. Braun, and F. Dominici (2020). Exposure to air pollution and COVID-19 mortality in the United States: A nationwide cross-sectional study. medRxiv. 


\section{Tables}

Table 1: Summary Statistics

\begin{tabular}{|c|c|c|c|c|}
\hline & Mean & S.E. & Min & Max \\
\hline \multicolumn{5}{|l|}{ County-Level Air Pollution } \\
\hline Weigthed PM 2.5 & 6.772 & 4.610 & 0.000 & 357.300 \\
\hline Air Quality Index & 27.334 & 14.746 & 0.000 & 335.500 \\
\hline \multicolumn{5}{|l|}{ County-Level Coronavirus Cases and Deaths } \\
\hline Rates of new cases per 100k people & 6.394 & 15.533 & 0.000 & 609.652 \\
\hline Daily count of new cases & 34.938 & 149.755 & 0.000 & 7198.000 \\
\hline Rates of new deaths per 100k people & 0.189 & 0.831 & 0.000 & 62.826 \\
\hline Daily count of new deaths & 1.179 & 9.586 & 0.000 & 1553.000 \\
\hline \multicolumn{5}{|l|}{ State-level Policies } \\
\hline Limiting Mass Gatherings & 0.347 & 0.476 & 0.000 & 1.000 \\
\hline Social Distancing & 0.347 & 0.476 & 0.000 & 1.000 \\
\hline Stay at Home, Quarantine, or Lockdown Orders & 0.268 & 0.443 & 0.000 & 1.000 \\
\hline School Closures & 0.256 & 0.437 & 0.000 & 1.000 \\
\hline Policies to Increase Testing & 0.420 & 0.494 & 0.000 & 1.000 \\
\hline Policies to Close State Borders & 0.148 & 0.355 & 0.000 & 1.000 \\
\hline Policies to Clean Public Surfaces & 0.130 & 0.336 & 0.000 & 1.000 \\
\hline Curfew & 0.039 & 0.193 & 0.000 & 1.000 \\
\hline Information Campaigns & 0.537 & 0.499 & 0.000 & 1.000 \\
\hline Declaration of State of Emergency & 0.531 & 0.499 & 0.000 & 1.000 \\
\hline Administrative Task Force Created & 0.411 & 0.492 & 0.000 & 1.000 \\
\hline Policies to Increase Access to PPE & 0.284 & 0.451 & 0.000 & 1.000 \\
\hline Policies to Increase Healthcare Resources & 0.389 & 0.487 & 0.000 & 1.000 \\
\hline \multicolumn{5}{|l|}{ County-Level Social Distancing Information } \\
\hline Change to average distance traveled from baseline & -0.136 & 0.178 & -0.830 & 1.080 \\
\hline Change to visits to non-essential locations from baseline & -0.205 & 0.394 & -1.000 & 14.956 \\
\hline Rate of unique human encounters per sq $\mathrm{km}$ relative to baseline & 3.503 & 60.439 & -1.000 & 5675.082 \\
\hline 2-week lagged average change in distance traveled from baseline & -0.134 & 0.164 & -0.761 & 0.719 \\
\hline 2-week lagged average change in visits from baseline & -0.202 & 0.371 & -0.967 & 11.705 \\
\hline 2-week lagged average rate of human encounters & 3.397 & 51.185 & -1.000 & 4268.316 \\
\hline County-Day Observations & 112,553 & & & \\
\hline County Observations & 622 & & & \\
\hline
\end{tabular}

Reported statistics are at the county-day level. Note that only counties with air pollution monitors are included. 
Table 2: Wind and PM 2.5 IV: Confirmed COVID-19 Cases

\begin{tabular}{|c|c|c|c|c|c|c|}
\hline & $\begin{array}{c}(1) \\
\text { Rates }\end{array}$ & $\begin{array}{c}(2) \\
\text { Rates }\end{array}$ & $\begin{array}{c}(3) \\
\text { Rates }\end{array}$ & $\begin{array}{c}(4) \\
\text { Totals }\end{array}$ & $\begin{array}{c}(5) \\
\text { Totals }\end{array}$ & $\begin{array}{c}(6) \\
\text { Totals }\end{array}$ \\
\hline PM 2.5 & $\begin{array}{l}0.131^{* * *} \\
(0.0506)\end{array}$ & $\begin{array}{l}0.115^{* * *} \\
(0.0413)\end{array}$ & $\begin{array}{l}0.108^{* *} \\
(0.0421)\end{array}$ & $\begin{array}{l}5.361 \\
(5.263)\end{array}$ & $\begin{array}{l}4.068 \\
(4.109)\end{array}$ & $\begin{array}{l}5.051 \\
(4.470)\end{array}$ \\
\hline F Stat & 248.68 & 1187.42 & 863.40 & 248.68 & 1189.09 & 863.33 \\
\hline Dep Var Mean & 6.356 & 6.356 & 6.356 & 34.170 & 34.170 & 34.171 \\
\hline Pct Change Mean & 2.063 & 1.803 & 1.707 & 15.690 & 11.906 & 14.781 \\
\hline Controls & $\checkmark$ & $\checkmark$ & $\checkmark$ & $\checkmark$ & $\checkmark$ & $\checkmark$ \\
\hline County \& State-by-Week FEs & $\checkmark$ & & & $\checkmark$ & & \\
\hline County and MSA-by-Week FEs & & $\checkmark$ & & & $\checkmark$ & \\
\hline County and CBSA-by-Week FEs & & & $\checkmark$ & & & $\checkmark$ \\
\hline Observations & 107,171 & 107,154 & 107,160 & 106,968 & 106,951 & 106,957 \\
\hline \multicolumn{7}{|c|}{$\begin{array}{l}{ }^{*} p<0.1,{ }^{* *} p<0.05,{ }^{* *} p<0.01 \text {. Standard errors clustered at the county in parentheses. Controls include state-level } \\
\text { policy adoption, wind speed dummies, social distancing information, day-of-week dummies, and two lagged wind direction } \\
\text { by monitor cluster dummies. Regressions on counts use county population as analytic weights. Displayed output of a two } \\
\text { stage-least squares regression model with county and state-by-week, MSA-by-week, or CBSA-by-week fixed effects in which } \\
\text { wind direction and location interactions are used to predict PM } 2.5 \text { levels in a county on a given day. Fitted pollution value } \\
\text { are then used to predict county-level COVID-19 cases. F statistics computed assuming first-stage standard errors are het- } \\
\text { eroskedastic. }\end{array}$} \\
\hline
\end{tabular}


Table 3: Wind and PM 2.5 IV: Confirmed COVID-19 Deaths

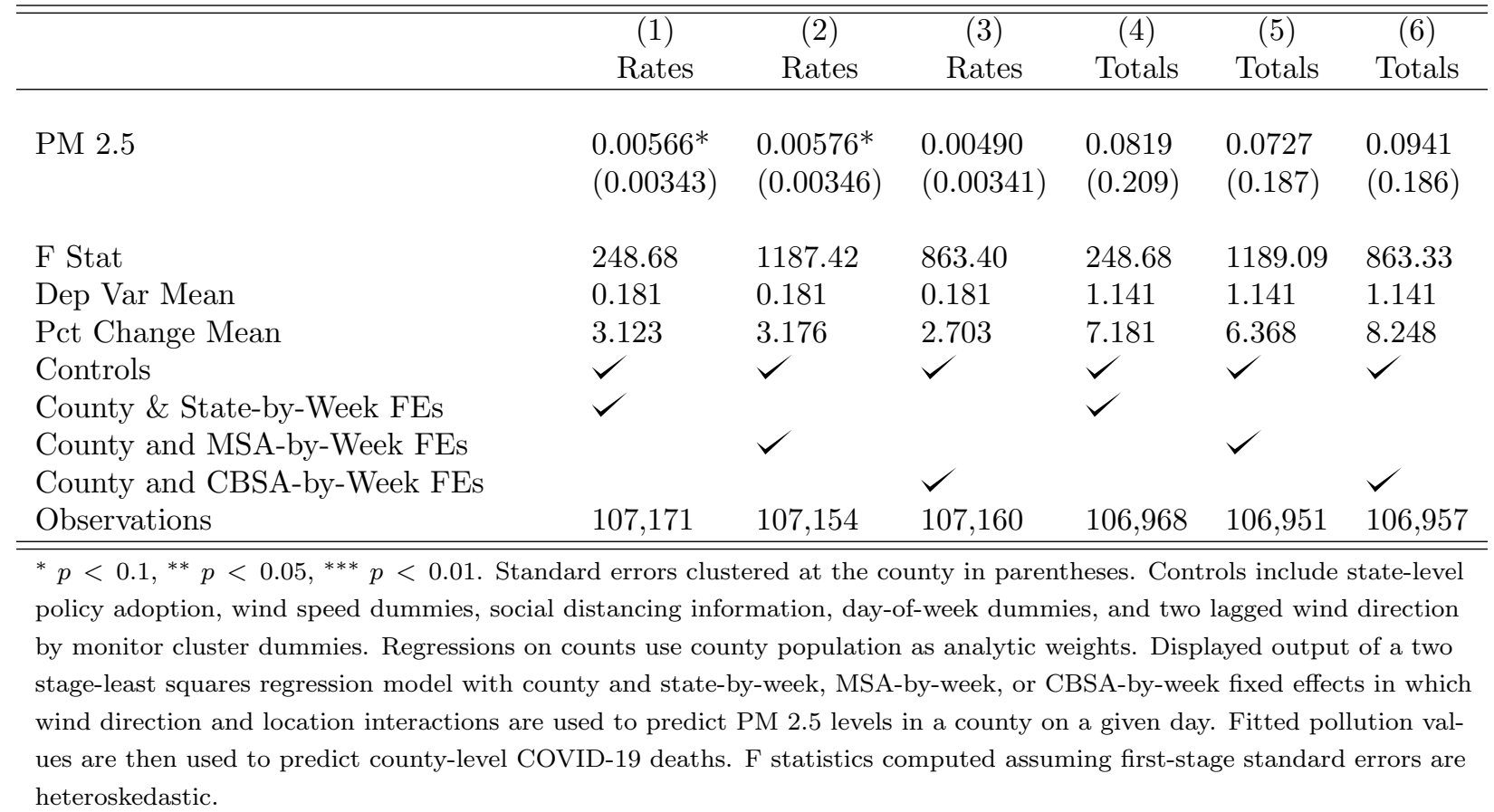


Table 4: Wind and PM 2.5 IV: Confirmed COVID-19 Cases across 1, 3, 7, 10, and 14 Day Periods

\begin{tabular}{|c|c|c|c|c|c|}
\hline & $\begin{array}{c}(1) \\
\text { Same Day }\end{array}$ & $\begin{array}{c}(2) \\
\text { 3-Day Total } \\
\end{array}$ & $\begin{array}{c}\text { (3) } \\
\text { 7-Day Total }\end{array}$ & $\begin{array}{c}(4) \\
\text { 10-Day Total }\end{array}$ & $\begin{array}{c}5) \\
\text { 14-Day Total }\end{array}$ \\
\hline \multicolumn{6}{|l|}{ Case Rate per 100,000 } \\
\hline PM 2.5 & $\begin{array}{l}0.131^{* * *} \\
(0.0506)\end{array}$ & $\begin{array}{l}0.296^{* *} \\
(0.120)\end{array}$ & $\begin{array}{l}0.167 \\
(0.252)\end{array}$ & $\begin{array}{l}0.368 \\
(0.365)\end{array}$ & $\begin{array}{l}0.434 \\
(0.528)\end{array}$ \\
\hline F Stat & 248.68 & 299.01 & 431.86 & 429.38 & 446.88 \\
\hline Dep Var Mean & 6.356 & 19.135 & 45.102 & 64.903 & 91.753 \\
\hline Pct Change Mean & 2.063 & 1.547 & 0.371 & 0.567 & 0.473 \\
\hline Controls & $\checkmark$ & $\checkmark$ & $\checkmark$ & $\checkmark$ & $\checkmark$ \\
\hline County \& State-by-Week FEs & $\checkmark$ & $\checkmark$ & $\checkmark$ & $\checkmark$ & $\checkmark$ \\
\hline Observations & 107,171 & 105,297 & 101,766 & 99,276 & 96,077 \\
\hline \multicolumn{6}{|l|}{ Case Totals } \\
\hline PM 2.5 & $\begin{array}{l}5.361 \\
(5.263)\end{array}$ & $\begin{array}{l}23.22 \\
(16.56)\end{array}$ & $\begin{array}{l}52.54 \\
(40.57)\end{array}$ & $\begin{array}{l}79.30 \\
(60.22)\end{array}$ & $\begin{array}{l}110.8 \\
(86.65)\end{array}$ \\
\hline F Stat & 248.68 & 299.99 & 431.96 & 429.59 & 447.70 \\
\hline Dep Var Mean & 34.170 & 103.317 & 245.147 & 354.298 & 503.644 \\
\hline Pct Change Mean & 15.690 & 22.476 & 21.432 & 22.383 & 22.002 \\
\hline Controls & $\checkmark$ & $\checkmark$ & $\checkmark$ & $\checkmark$ & $\checkmark$ \\
\hline County \& State-by-Week FEs & $\checkmark$ & $\checkmark$ & $\checkmark$ & $\checkmark$ & $\checkmark$ \\
\hline Observations & 106,968 & 105,098 & 101,575 & 99,091 & 95,900 \\
\hline
\end{tabular}

${ }^{*} p<0.1,{ }^{* *} p<0.05,{ }^{* * *} p<0.01$. Standard errors clustered at the county in parentheses. Controls include state-level policy adoption, wind speed dummies, social distancing information, day-of-week dummies, and two lagged wind direction by monitor cluster dummies. Regressions on counts use county population as analytic weights. Displayed output of a two stage-least squares regression model with county and state-by-week fixed effects. Column (1) regresses wind-induced fine particulate matter on the number of cases on the same day. Column (2) regresses fine particulate matter on the number of cases over the same day and the following two days. Column (3) regresses fine particulate matter on the number of cases over the same day and the following nine days. Column (4) regresses fine particulate matter on the number of cases over the same day and the following thirteen days. F statistics computed assuming first-stage standard errors are heteroskedastic. 
Table 5: Wind and PM 2.5 IV: Confirmed COVID-19 Deaths across 1, 3, 7, 10, and 14 Day Periods

\begin{tabular}{|c|c|c|c|c|c|}
\hline & $\begin{array}{c}1) \\
\text { Same Day }\end{array}$ & $\begin{array}{c}(2) \\
\text { 3-Day Total }\end{array}$ & $\begin{array}{c}\text { (3) } \\
\text { 7-Day Total }\end{array}$ & $\begin{array}{c}(4) \\
\text { 10-Day Total }\end{array}$ & $\begin{array}{c}(5) \\
\text { 14-Day Total }\end{array}$ \\
\hline \multicolumn{6}{|l|}{ Death Rate per 100,000} \\
\hline PM 2.5 & $\begin{array}{l}0.00566^{*} \\
(0.00343)\end{array}$ & $\begin{array}{l}0.00591 \\
(0.00602)\end{array}$ & $\begin{array}{l}-0.00861 \\
(0.0125)\end{array}$ & $\begin{array}{l}-0.0115 \\
(0.0162)\end{array}$ & $\begin{array}{l}-0.0132 \\
(0.0206)\end{array}$ \\
\hline $\begin{array}{l}\text { F Stat } \\
\text { Dep Var Mean } \\
\text { Pct Change Mean } \\
\text { Controls } \\
\text { County \& State-by-Week FEs } \\
\text { Observations }\end{array}$ & $\begin{array}{l}248.68 \\
0.181 \\
3.123 \\
\checkmark \\
107,171\end{array}$ & $\begin{array}{l}299.01 \\
0.544 \\
1.086 \\
\checkmark \\
105,297\end{array}$ & $\begin{array}{l}431.86 \\
1.278 \\
-0.674 \\
\checkmark \\
101,766\end{array}$ & $\begin{array}{l}429.38 \\
1.832 \\
-0.627 \\
\checkmark \\
\checkmark 99,276\end{array}$ & $\begin{array}{l}446.88 \\
2.582 \\
-0.511 \\
\checkmark \\
96,077\end{array}$ \\
\hline \multicolumn{6}{|l|}{ Death Totals } \\
\hline PM 2.5 & $\begin{array}{l}0.0819 \\
(0.209)\end{array}$ & $\begin{array}{l}0.400 \\
(0.515)\end{array}$ & $\begin{array}{l}0.308 \\
(1.065)\end{array}$ & $\begin{array}{l}0.716 \\
(1.378)\end{array}$ & $\begin{array}{l}1.916 \\
(1.864)\end{array}$ \\
\hline F Stat & 248.68 & 299.99 & 431.96 & 429.59 & 447.70 \\
\hline Dep Var Mean & 1.141 & 3.441 & 8.156 & 11.771 & 16.707 \\
\hline Pct Change Mean & 7.181 & 11.621 & 3.778 & 6.080 & 11.467 \\
\hline Controls & $\checkmark$ & $\checkmark$ & $\checkmark$ & $\checkmark$ & $\checkmark$ \\
\hline County \& State-by-Week FEs & $\checkmark$ & $\checkmark$ & $\checkmark$ & $\checkmark$ & $\checkmark$ \\
\hline Observations & 106,968 & 105,098 & 101,575 & 99,091 & 95,900 \\
\hline
\end{tabular}

${ }^{*} p<0.1,{ }^{* *} p<0.05,{ }^{* * *} p<0.01$. Standard errors clustered at the county in parentheses. Controls include state-level policy adoption, wind speed dummies, social distancing information, day-of-week dummies, and two lagged wind direction by monitor cluster dummies. Regressions on counts use county population as analytic weights. Displayed output of a two stageleast squares regression model with county and state-by-week fixed effects. Column (1) regresses wind-induced fine particulate matter on the number of deaths on the same day. Column (2) regresses fine particulate matter on the number of deaths over the same day and the following two days. Column (3) regresses fine particulate matter on the number of deaths over the same day and the following nine days. Column (4) adopts a dependent variable of the number of deaths on the same day and the following thirteen days. F statistics computed assuming first-stage standard errors are heteroskedastic. 


\section{Figures}

Figure 1: New Confirmed COVID-19 Cases and Deaths in the United States
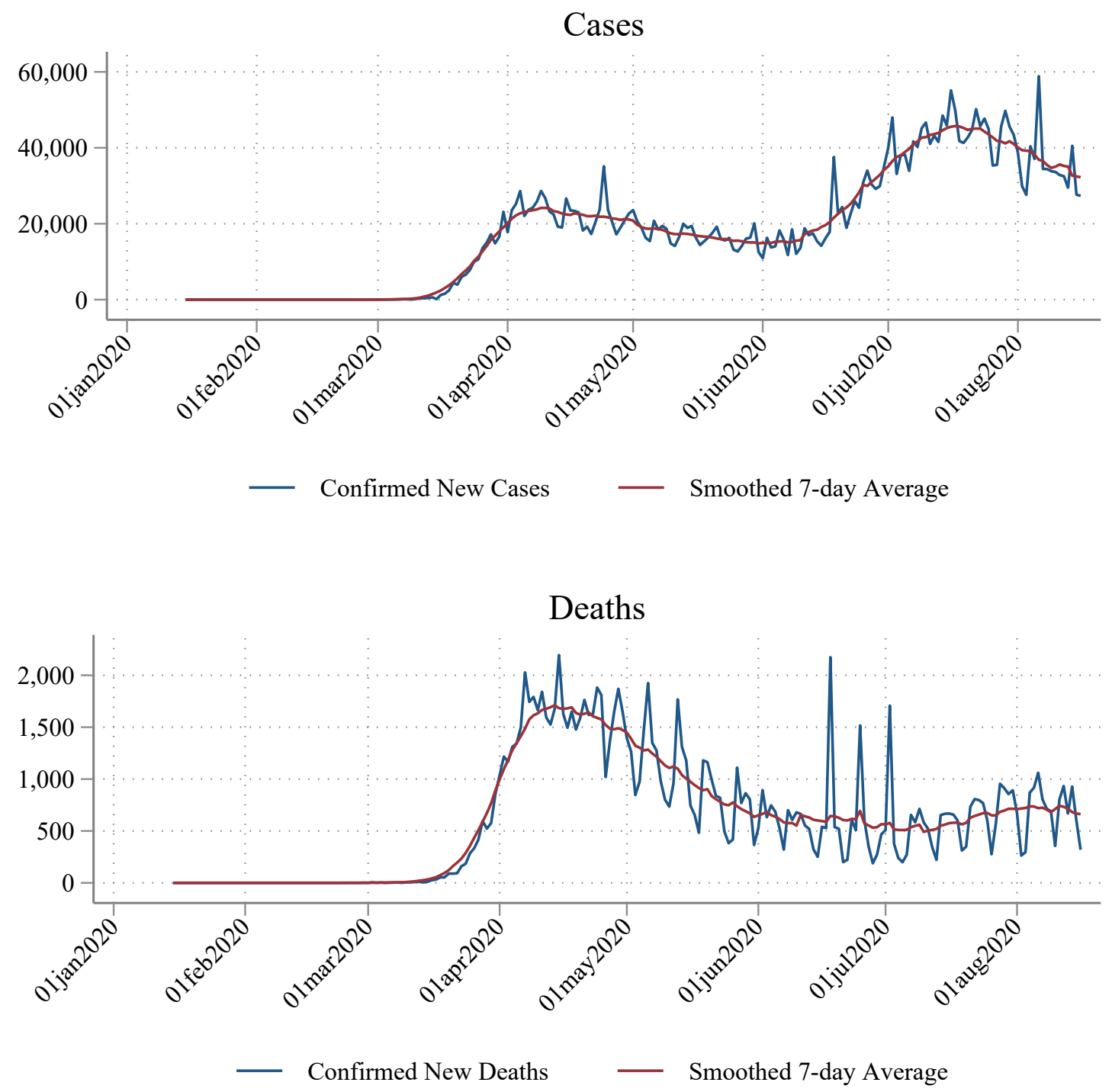

Notes: Cases and deaths sourced from the Johns Hopkins COVID-19 Data Repository. Smoothed average calculated with seven lead and seven lag days. 
Figure 2: New Confirmed Cases per 100,000 People by US County

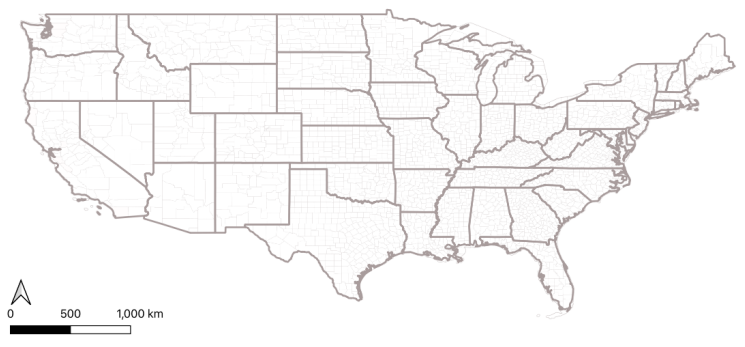

(a) February

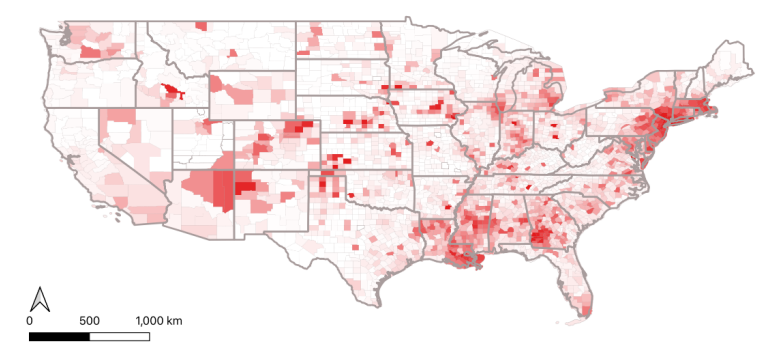

(c) April

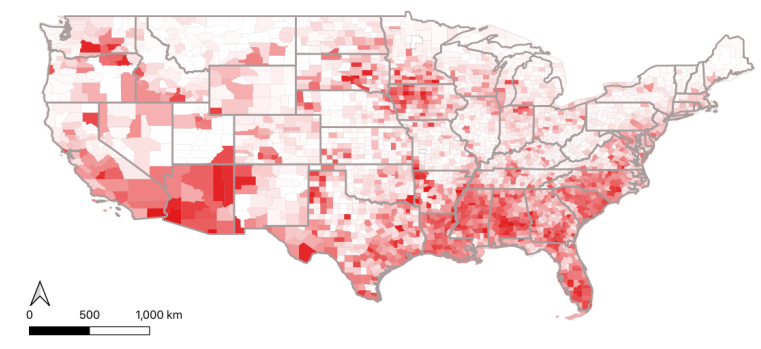

(e) June

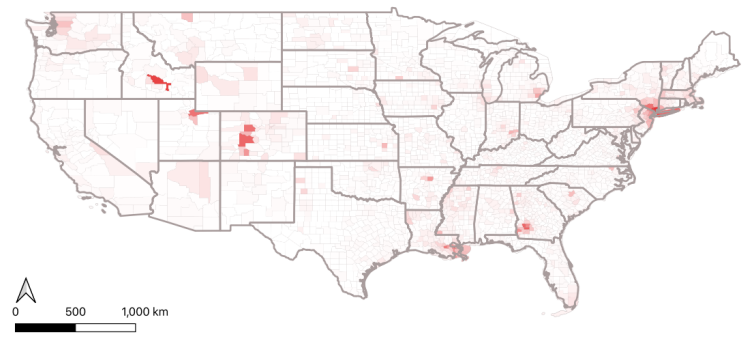

(b) March

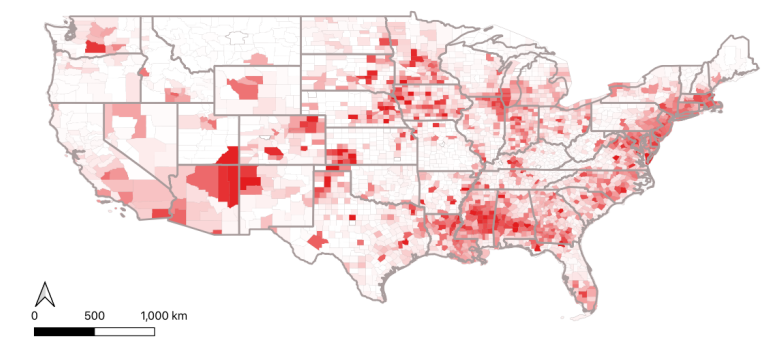

(d) May

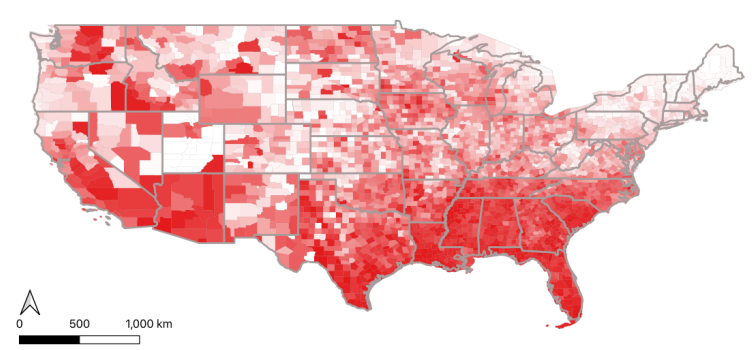

(f) July

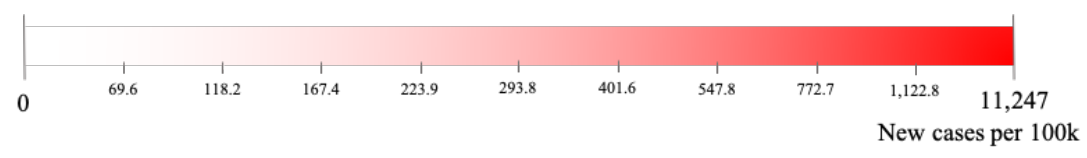

Notes: Cases and deaths sourced from the Johns Hopkins COVID-19 Data Repository. 
Figure 3: EPA's Air Quality Monitors

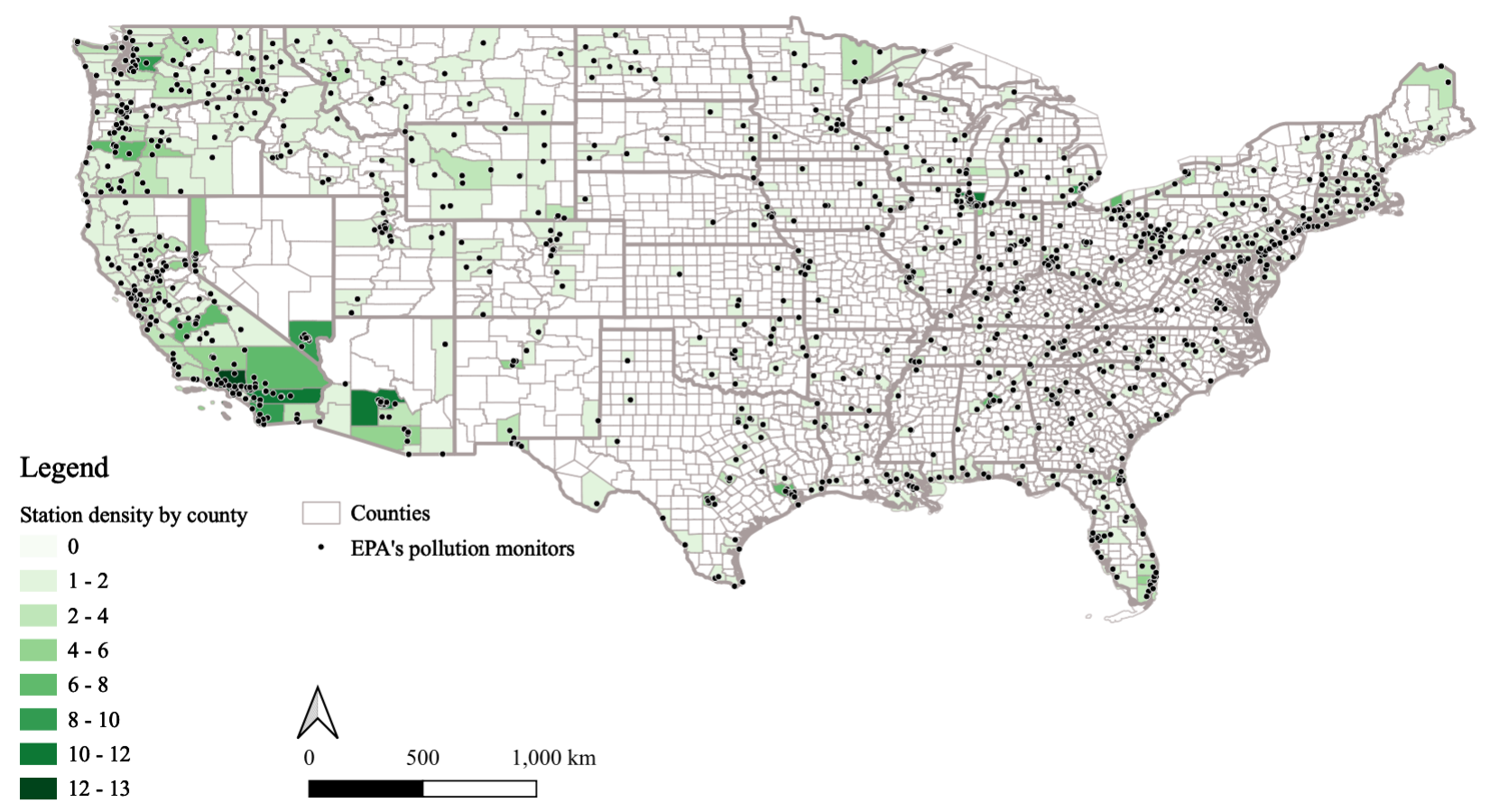

Notes: Each dot represents an EPA air quality monitor reporting PM 2.5 in 2020. 
Figure 4: EPA Air Quality Monitor Clusters

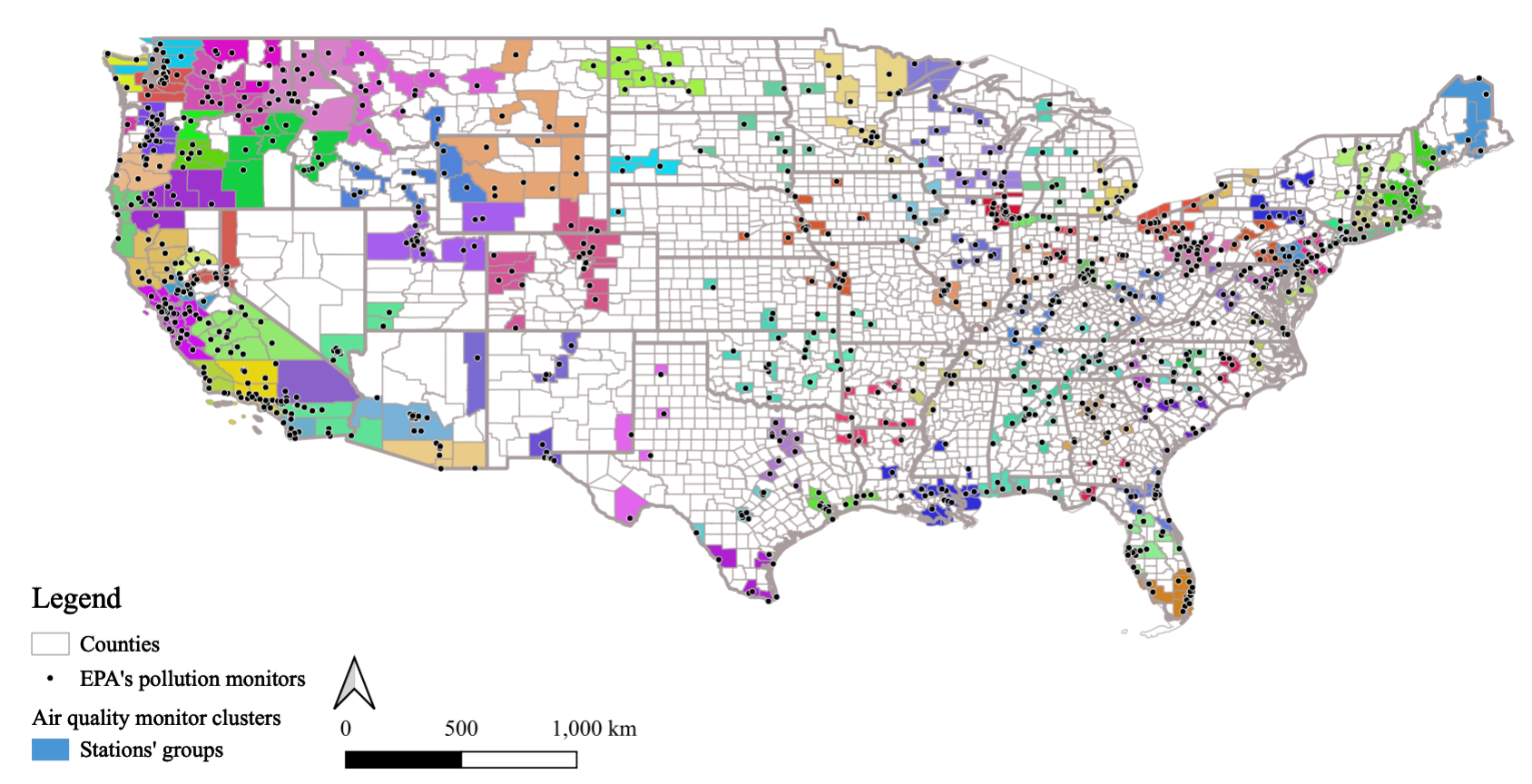

Notes: Each color represents one of 100 air quality monitor clusters. These clusters are grouped according to the location of the stations following the strategy proposed by Deryugina et al. (2019). 
Figure 5: Fine Particulate Mean Daily Concentration by Month and County

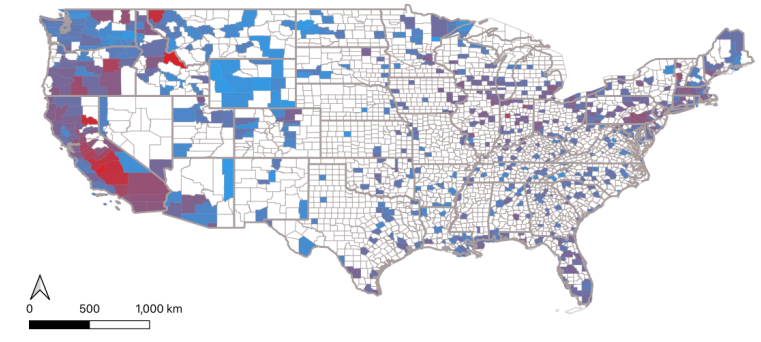

(a) February

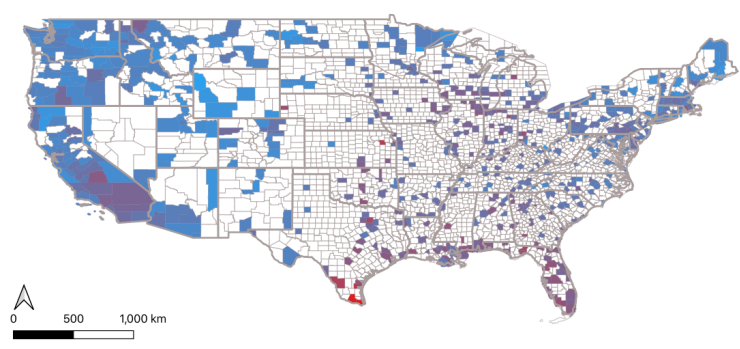

(c) April

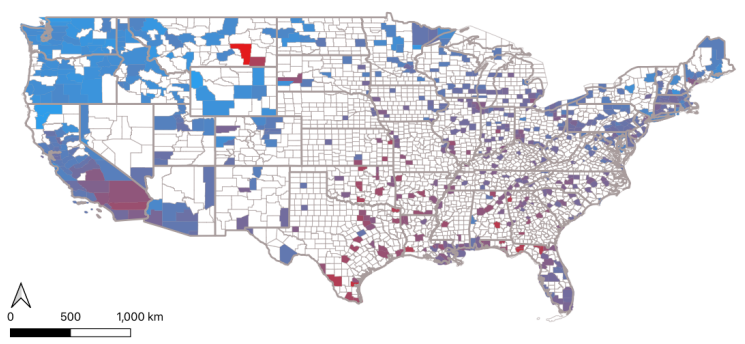

(e) June

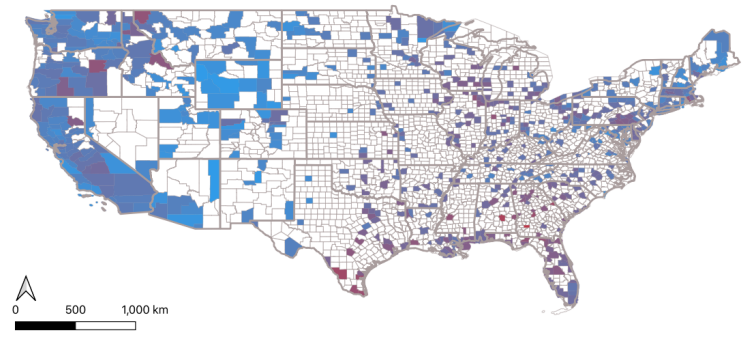

(b) March

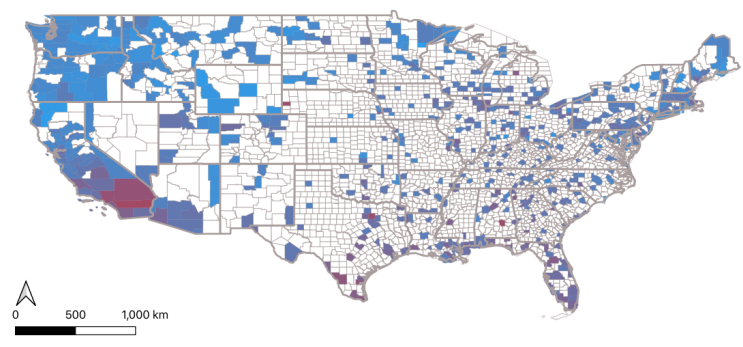

(d) May

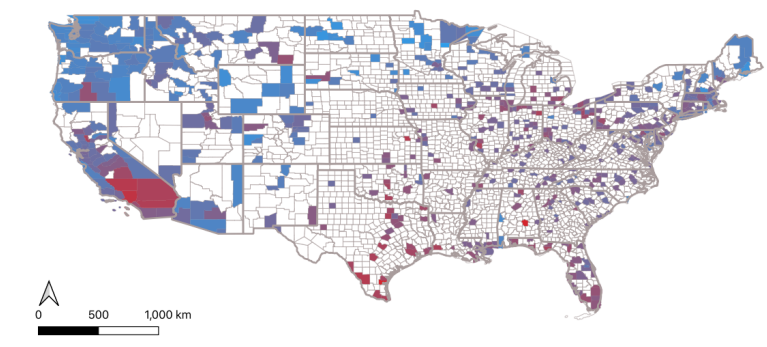

(f) July

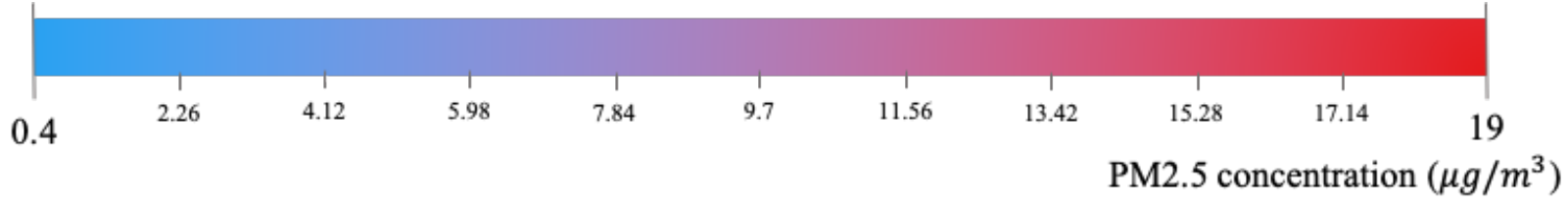

Notes: For each county, the value for each month is calculated by averaging the daily concentration of PM 2.5 , weighted by the number of people in census blocks in a 10 kilometer buffer around the station 
Figure 6: Air Quality During the Pandemic

\section{Fine Particulate Matter Concentration}

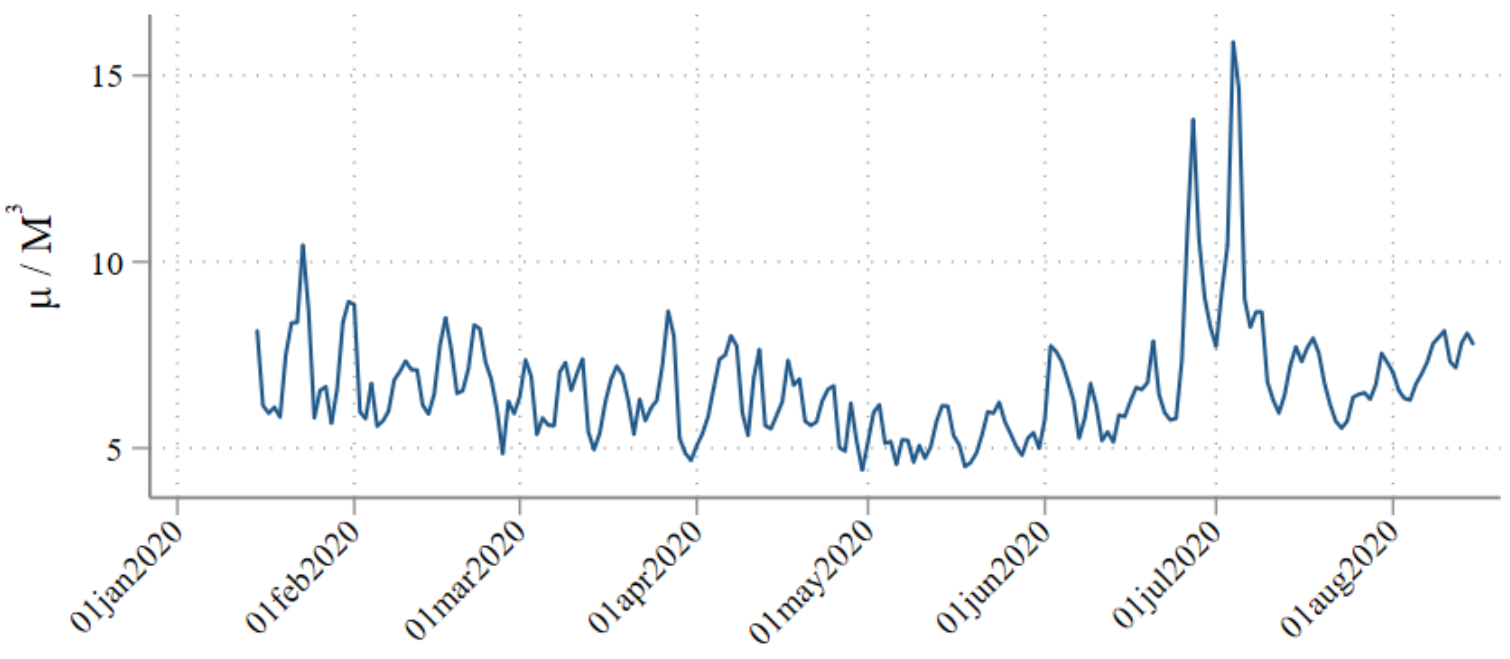

\section{Air Quality Index}

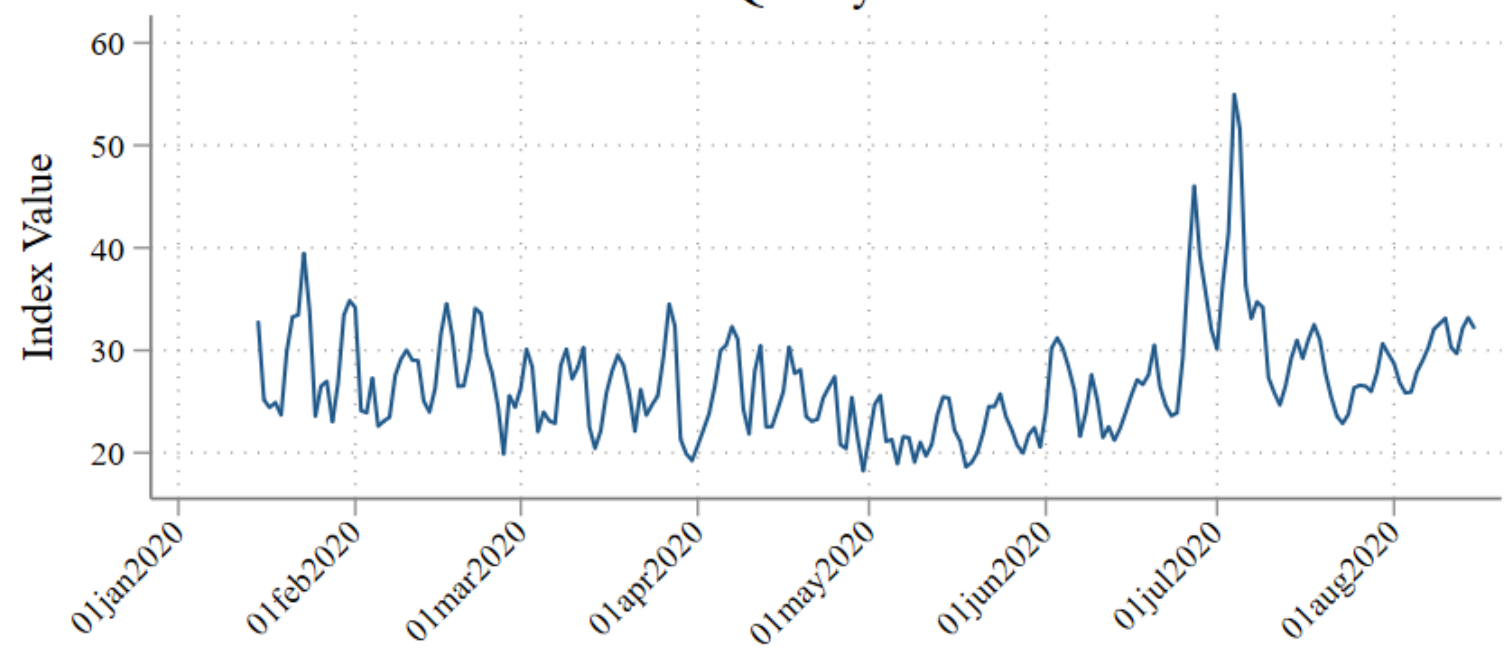

Notes: Figures plot average county-level fine particulate matter or air quality index on each date. County-level figures derived by averaging values over all monitors reporting on any given day. 
Figure 7: NOAA Wind and Weather Monitoring Stations

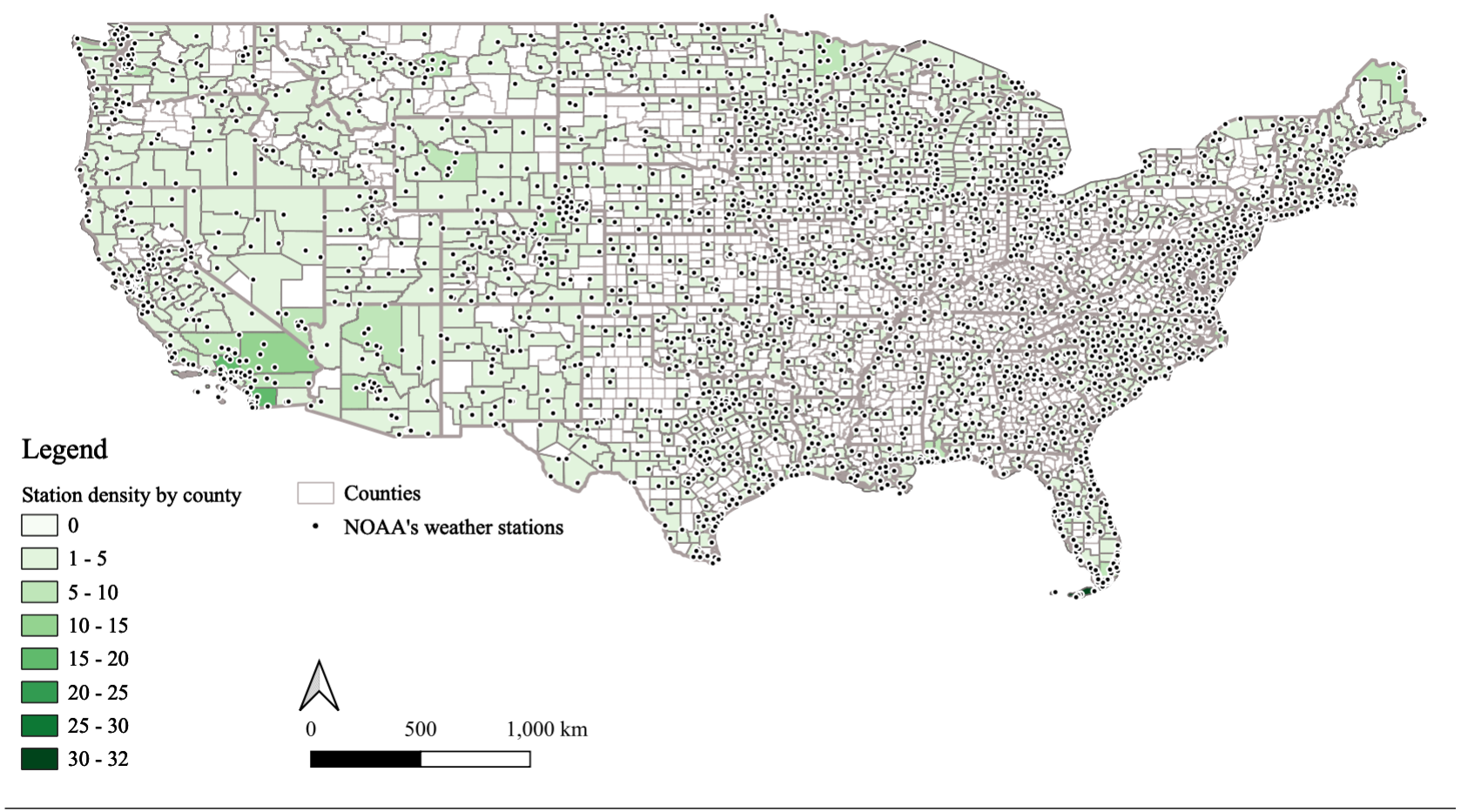

Notes: Each dot represents a weather station reporting wind speed and direction in 2020. 


\section{Appendix}

Table A1: Wind and Air Quality Index IV: Confirmed COVID-19 Cases and Deaths

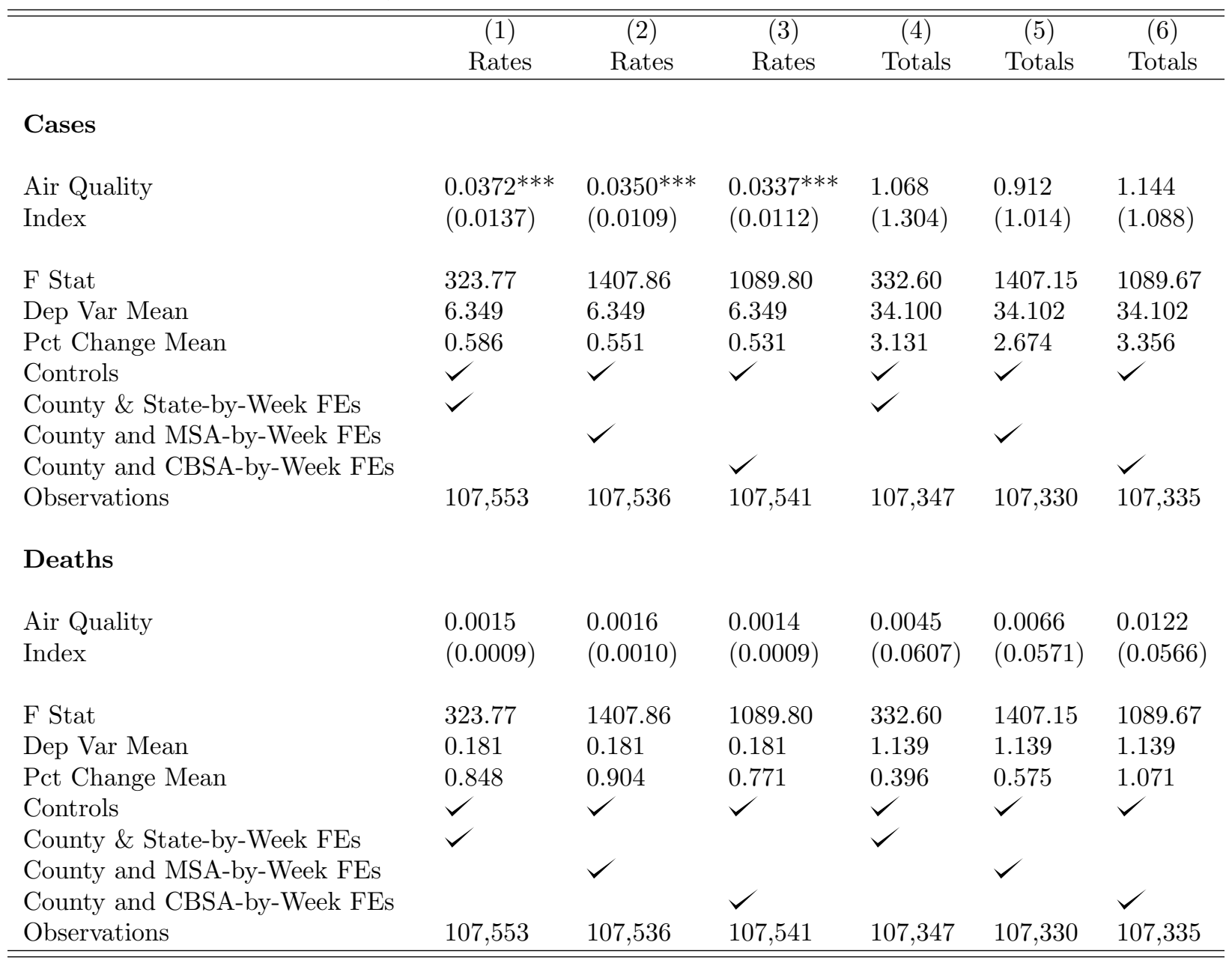

${ }^{*} p<0.1,{ }^{* *} p<0.05,{ }^{* * *} p<0.01$. Standard errors clustered at the county in parentheses. Controls include state-level policy adoption, wind speed dummies, social distancing information, day-of-week dummies, and two lagged wind direction by monitor cluster dummies. Regressions on counts use county population as analytic weights. Displayed output of a two stageleast squares regression model with county and state-by-week, MSA-by-week, or CBSA-by-week fixed effects in which wind direction and location interactions are used to predict EPA Air Quality Index in a county on a given day. Fitted AQI levels are then used to predict county-level COVID-19 cases or deaths. F statistics computed assuming first-stage standard errors are heteroskedastic. 


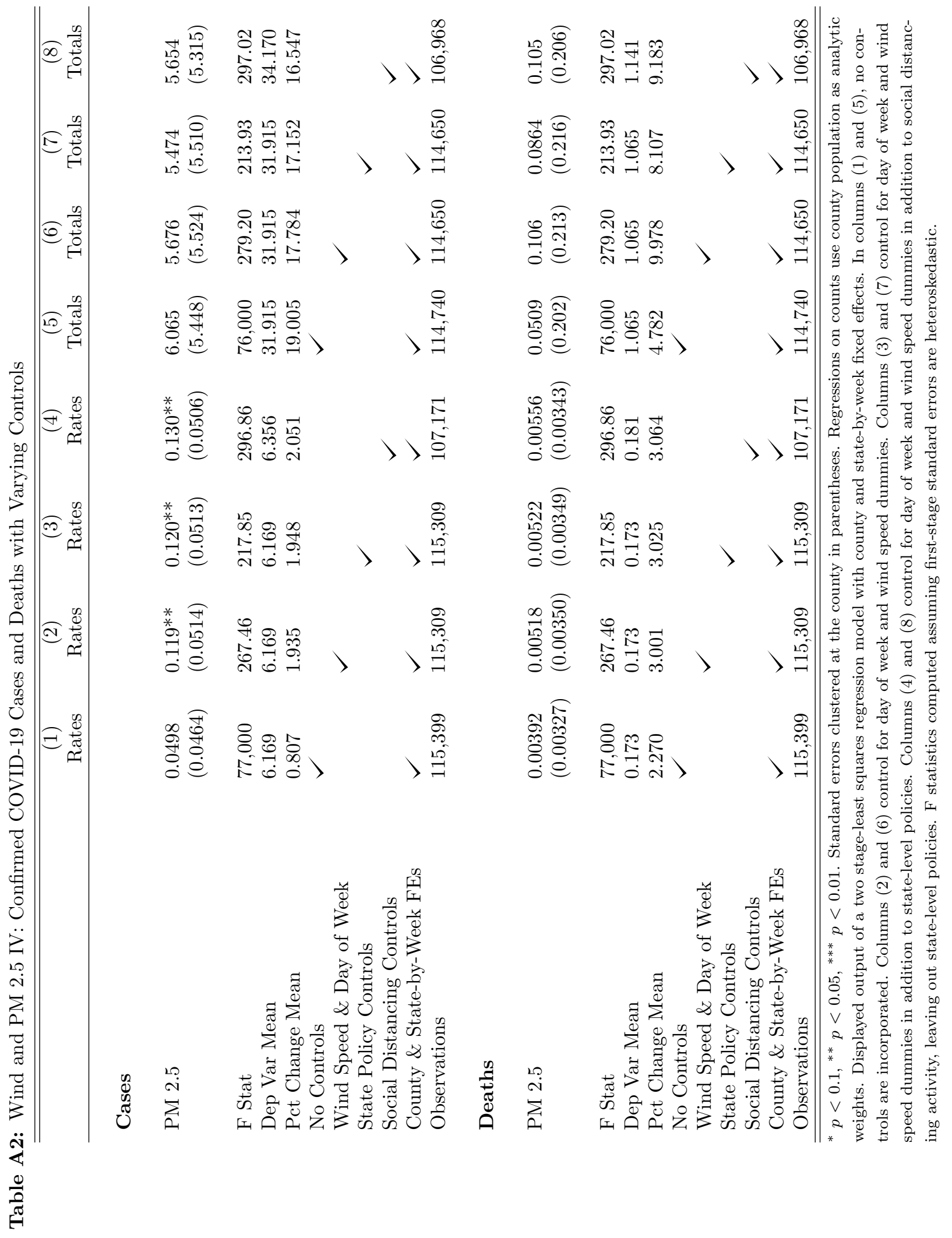


Table A3: Sensitivity of the Analysis to Inclusion of Social Distancing Controls

\begin{tabular}{|c|c|c|c|c|c|c|}
\hline & $\begin{array}{c}(1) \\
\text { Rates }\end{array}$ & $\begin{array}{c}(2) \\
\text { Rates }\end{array}$ & $\begin{array}{c}(3) \\
\text { Rates }\end{array}$ & $\begin{array}{c}(4) \\
\text { Totals }\end{array}$ & $\begin{array}{c}(5) \\
\text { Totals }\end{array}$ & $\begin{array}{c}(6) \\
\text { Totals }\end{array}$ \\
\hline \multicolumn{7}{|l|}{ Cases } \\
\hline PM 2.5 & $\begin{array}{l}0.120^{* *} \\
(0.0513)\end{array}$ & $\begin{array}{l}0.103^{* *} \\
(0.0419)\end{array}$ & $\begin{array}{l}0.0958^{* *} \\
(0.0422)\end{array}$ & $\begin{array}{l}5.474 \\
(5.510)\end{array}$ & $\begin{array}{l}3.824 \\
(4.228)\end{array}$ & $\begin{array}{l}5.091 \\
(4.756)\end{array}$ \\
\hline F Stat & 213.93 & 695.32 & 675.78 & 213.93 & 695.32 & 670.35 \\
\hline Dep Var Mean & 6.169 & 6.168 & 6.168 & 31.915 & 31.915 & 31.916 \\
\hline Pct Change Mean & 1.948 & 1.663 & 1.553 & 17.152 & 11.981 & 15.951 \\
\hline Controls & $\checkmark$ & $\checkmark$ & $\checkmark$ & $\checkmark$ & $\checkmark$ & $\checkmark$ \\
\hline County \& State-by-Week FEs & $\checkmark$ & & & $\checkmark$ & & \\
\hline County and MSA-by-Week FEs & & $\checkmark$ & & & $\checkmark$ & \\
\hline County and CBSA-by-Week FEs & & & $\checkmark$ & & & $\checkmark$ \\
\hline Observations & 115,309 & 115,292 & 115,298 & 114,650 & 114,633 & 114,639 \\
\hline \multicolumn{7}{|l|}{ Deaths } \\
\hline PM 2.5 & $\begin{array}{l}0.00522 \\
(0.00349)\end{array}$ & $\begin{array}{l}0.00564 \\
(0.00349)\end{array}$ & $\begin{array}{l}0.00494 \\
(0.00347)\end{array}$ & $\begin{array}{l}0.0864 \\
(0.216)\end{array}$ & $\begin{array}{l}0.0630 \\
(0.188)\end{array}$ & $\begin{array}{c}0.0914 \\
(0.191)\end{array}$ \\
\hline F Stat & 213.93 & 695.32 & 675.78 & 213.93 & 695.32 & 670.35 \\
\hline Dep Var Mean & 0.173 & 0.173 & 0.173 & 1.065 & 1.065 & 1.065 \\
\hline Pct Change Mean & 3.025 & 3.264 & 2.859 & 8.107 & 5.913 & 8.576 \\
\hline Controls & $\checkmark$ & $\checkmark$ & $\checkmark$ & $\checkmark$ & $\checkmark$ & $\checkmark$ \\
\hline County \& State-by-Week FEs & $\checkmark$ & & & $\checkmark$ & & \\
\hline County and MSA-by-Week FEs & & $\checkmark$ & & & $\checkmark$ & \\
\hline County and CBSA-by-Week FEs & & & $\checkmark$ & & & $\checkmark$ \\
\hline Observations & 115,309 & 115,292 & 115,298 & 114,650 & 114,633 & 114,639 \\
\hline
\end{tabular}

${ }^{*} p<0.1,{ }^{* *} p<0.05,{ }^{* * *} p<0.01$. Standard errors clustered at the county in parentheses. Controls include state-level policy adoption, wind speed dummies, day-of-week dummies, and two lagged wind direction by monitor cluster dummies. Regressions on counts use county population as analytic weights. Displayed output of a two stage-least squares regression model with county and state-by-week, MSA-by-week, or CBSA-by-week fixed effects in which wind direction and location interactions are used to predict PM 2.5 levels in a county on a given day. Fitted pollution values are then used to predict county-level COVID-19 cases and deaths. F statistics computed assuming first-stage standard errors are heteroskedastic. 
Table A4: Sensitivity of the Analysis to Dropping New York City Region

\begin{tabular}{|c|c|c|c|c|c|c|}
\hline & $\begin{array}{c}(1) \\
\text { Rates }\end{array}$ & $\begin{array}{c}(2) \\
\text { Rates }\end{array}$ & $\begin{array}{c}(3) \\
\text { Rates }\end{array}$ & $\begin{array}{c}(4) \\
\text { Totals }\end{array}$ & $\begin{array}{c}(5) \\
\text { Totals }\end{array}$ & $\begin{array}{c}(6) \\
\text { Totals }\end{array}$ \\
\hline \multicolumn{7}{|l|}{ Cases } \\
\hline PM 2.5 & $\begin{array}{l}0.152^{* * *} \\
(0.0501)\end{array}$ & $\begin{array}{l}0.124^{* * *} \\
(0.0415)\end{array}$ & $\begin{array}{l}0.120^{* * *} \\
(0.0423)\end{array}$ & $\begin{array}{l}6.898 \\
(5.199)\end{array}$ & $\begin{array}{l}5.511 \\
(4.091)\end{array}$ & $\begin{array}{l}6.226 \\
(4.457)\end{array}$ \\
\hline F Stat & 249.37 & 1181.48 & 860.58 & 249.39 & 1183.19 & 860.59 \\
\hline Dep Var Mean & 6.266 & 6.265 & 6.266 & 31.931 & 31.931 & 31.932 \\
\hline Pct Change Mean & 2.419 & 1.979 & 1.911 & 21.602 & 17.259 & 19.498 \\
\hline Controls & $\checkmark$ & $\checkmark$ & $\checkmark$ & $\checkmark$ & $\checkmark$ & $\checkmark$ \\
\hline County \& State-by-Week FEs & $\checkmark$ & & & $\checkmark$ & & \\
\hline County and MSA-by-Week FEs & & $\checkmark$ & & & $\checkmark$ & \\
\hline County and CBSA-by-Week FEs & & & $\checkmark$ & & & $\checkmark$ \\
\hline Observations & 106,086 & 106,068 & 106,074 & 105,883 & 105,865 & 105,871 \\
\hline \multicolumn{7}{|l|}{ Deaths } \\
\hline PM 2.5 & $\begin{array}{l}0.0090^{* * *} \\
(0.0032)\end{array}$ & $\begin{array}{l}0.0089 * * * \\
(0.0032)\end{array}$ & $\begin{array}{l}0.0079 * * \\
(0.0031)\end{array}$ & $\begin{array}{l}0.308^{* *} \\
(0.151)\end{array}$ & $\begin{array}{l}0.310^{* * *} \\
(0.108)\end{array}$ & $\begin{array}{l}0.314^{* * *} \\
(0.106)\end{array}$ \\
\hline F Stat & 249.37 & 1181.48 & 860.58 & 249.39 & 1183.19 & 860.59 \\
\hline Dep Var Mean & 0.170 & 0.170 & 0.170 & 0.918 & 0.918 & 0.918 \\
\hline Pct Change Mean & 5.275 & 5.199 & 4.648 & 33.504 & 33.706 & 34.201 \\
\hline Controls & $\checkmark$ & $\checkmark$ & $\checkmark$ & $\checkmark$ & $\checkmark$ & $\checkmark$ \\
\hline County \& State-by-Week FEs & $\checkmark$ & & & $\checkmark$ & & \\
\hline County and MSA-by-Week FEs & & $\checkmark$ & & & $\checkmark$ & \\
\hline County and CBSA-by-Week FEs & & & $\checkmark$ & & & \\
\hline Observations & 106,086 & 106,068 & 106,074 & 105,883 & 105,865 & 105,871 \\
\hline
\end{tabular}

${ }^{*} p<0.1,{ }^{* *} p<0.05,{ }^{* * *} p<0.01$. Standard errors clustered at the county in parentheses. Controls include state-level policy adoption, wind speed dummies, day-of-week dummies, social distancing information, and two lagged wind direction by monitor cluster dummies. Regressions on counts use county population as analytic weights. Displayed output of a two stageleast squares regression model with county and state-by-week, MSA-by-week, or CBSA-by-week fixed effects in which wind direction and location interactions are used to predict PM 2.5 levels in a county on a given day. Fitted pollution values are then used to predict county-level COVID-19 cases and deaths. F statistics computed assuming first-stage standard errors are heteroskedastic. 
Table A5: Ordinary Least Squares: PM 2.5 and Cases and Deaths

\begin{tabular}{|c|c|c|c|c|c|c|}
\hline & $\begin{array}{c}(1) \\
\text { Rates }\end{array}$ & $\begin{array}{c}(2) \\
\text { Rates }\end{array}$ & $\begin{array}{c}(3) \\
\text { Rates }\end{array}$ & $\begin{array}{c}(4) \\
\text { Totals }\end{array}$ & $\begin{array}{c}(5) \\
\text { Totals }\end{array}$ & $\begin{array}{c}(6) \\
\text { Totals }\end{array}$ \\
\hline \multicolumn{7}{|l|}{ Cases } \\
\hline PM 2.5 & $\begin{array}{l}0.0296 \\
(0.0197)\end{array}$ & $\begin{array}{l}0.0166 \\
(0.0149)\end{array}$ & $\begin{array}{l}0.0180 \\
(0.0153)\end{array}$ & $\begin{array}{l}5.914 \\
(4.567)\end{array}$ & $\begin{array}{l}5.859 \\
(4.679)\end{array}$ & $\begin{array}{l}5.917 \\
(4.675)\end{array}$ \\
\hline Dep Var Mean & 6.700 & 6.697 & 6.698 & 34.458 & 34.453 & 34.457 \\
\hline Pct Change Mean & 0.442 & 0.248 & 0.268 & 17.164 & 17.006 & 17.174 \\
\hline Controls & $\checkmark$ & $\checkmark$ & $\checkmark$ & $\checkmark$ & $\checkmark$ & $\checkmark$ \\
\hline County \& State-by-Week FEs & $\checkmark$ & & & $\checkmark$ & & \\
\hline County \& MSA-by-Week FEs & & $\checkmark$ & & & $\checkmark$ & \\
\hline County \& CBSA-by-Week FEs & & & $\checkmark$ & & & $\checkmark$ \\
\hline Observations & 112,957 & 112,944 & 112,939 & 112,551 & 112,539 & 112,534 \\
\hline \multicolumn{7}{|l|}{ Deaths } \\
\hline PM 2.5 & $\begin{array}{l}-0.00037 \\
(0.00061)\end{array}$ & $\begin{array}{l}-0.00050 \\
(0.00054)\end{array}$ & $\begin{array}{c}-0.00074 \\
(0.0006)\end{array}$ & $\begin{array}{l}0.00787 \\
(0.0256)\end{array}$ & $\begin{array}{l}0.00824 \\
(0.0227)\end{array}$ & $\begin{array}{l}0.00304 \\
(0.0222)\end{array}$ \\
\hline Dep Var Mean & 0.195 & 0.194 & 0.195 & 1.168 & 1.168 & 1.168 \\
\hline Pct Change Mean & -0.192 & -0.259 & -0.378 & 0.674 & 0.706 & 0.260 \\
\hline Controls & $\checkmark$ & $\checkmark$ & $\checkmark$ & $\checkmark$ & $\checkmark$ & $\checkmark$ \\
\hline County \& State-by-Week FEs & $\checkmark$ & & & $\checkmark$ & & \\
\hline County \& MSA-by-Week FEs & & $\checkmark$ & & & $\checkmark$ & \\
\hline County \& CBSA-by-Week FEs & & & $\checkmark$ & & & $\checkmark$ \\
\hline Observations & 112,957 & 112,944 & 112,939 & 112,551 & 112,539 & 112,534 \\
\hline
\end{tabular}

\footnotetext{
${ }^{*} p<0.1,{ }^{* *} p<0.05,{ }^{* * *} p<0.01$. Standard errors clustered at the county in parentheses. Controls include state-level policy adoption, wind speed dummies, day-of-week dummies, and social distancing information. Regressions on counts use county population as analytic weights. Displayed output of a reduced form ordinary least squares estimation of populationweighted county-level PM 2.5 on confirmed COVID-19 cases or deaths.
} 
Table A6: Sensitivity of the Analysis to Assigning Wind Direction Based on Nearest Weather Station

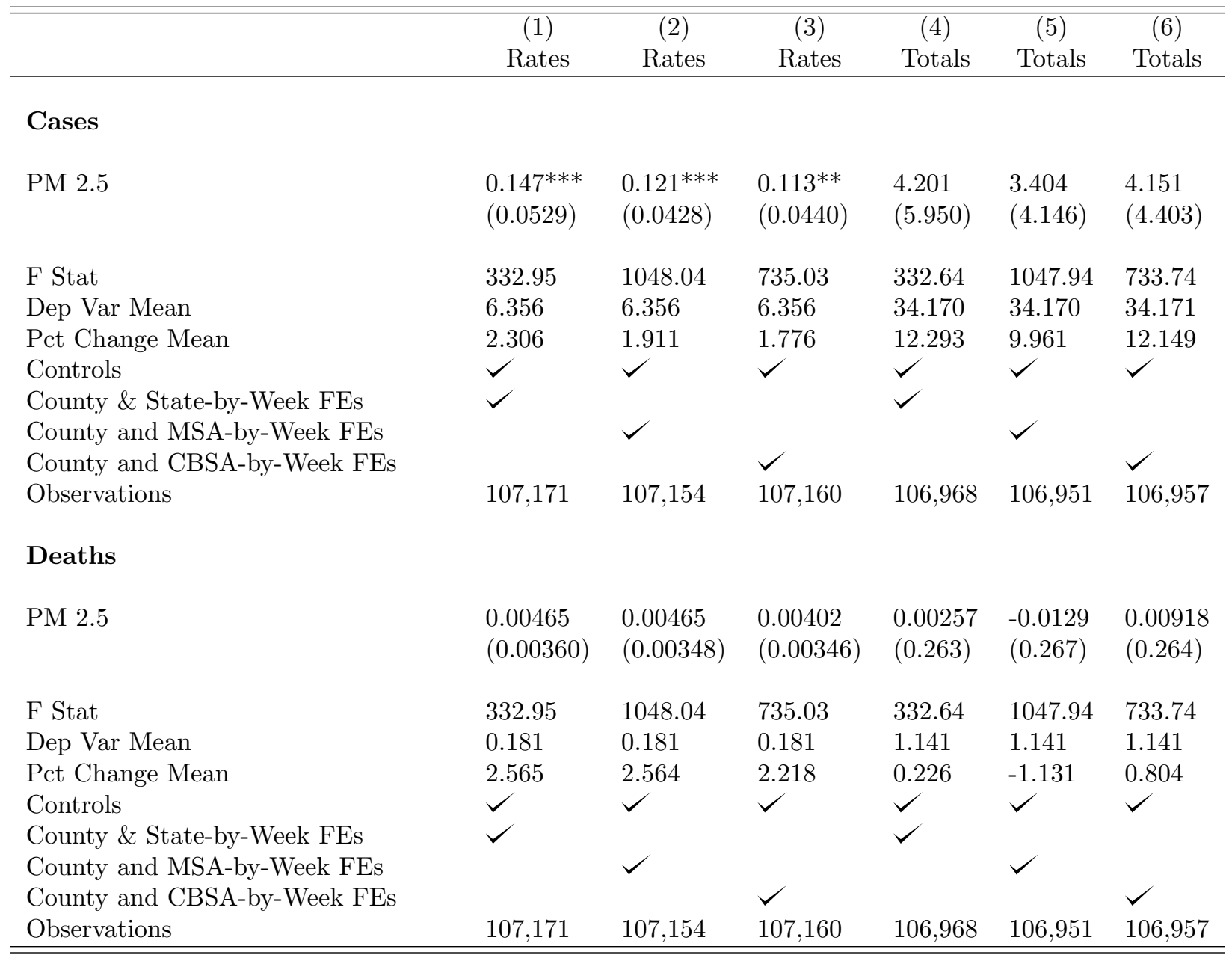

${ }^{*} p<0.1,{ }^{* *} p<0.05,{ }^{* * *} p<0.01$. Standard errors clustered at the county in parentheses. Controls include state-level policy adoption, wind speed dummies, day-of-week dummies, social distancing information, and two lagged wind direction by monitor cluster dummies. Regressions on counts use county population as analytic weights. Displayed output of a two stageleast squares regression model with county and state-by-week, MSA-by-week, or CBSA-by-week fixed effects in which wind direction and location interactions are used to predict PM 2.5 levels in a county on a given day. Fitted pollution values are then used to predict county-level COVID-19 cases and deaths. F statistics computed assuming first-stage standard errors are heteroskedastic. 
Table A7: Sensitivity of the Analysis to Assigning Wind Direction Based on Twelve Nearest Weather Stations

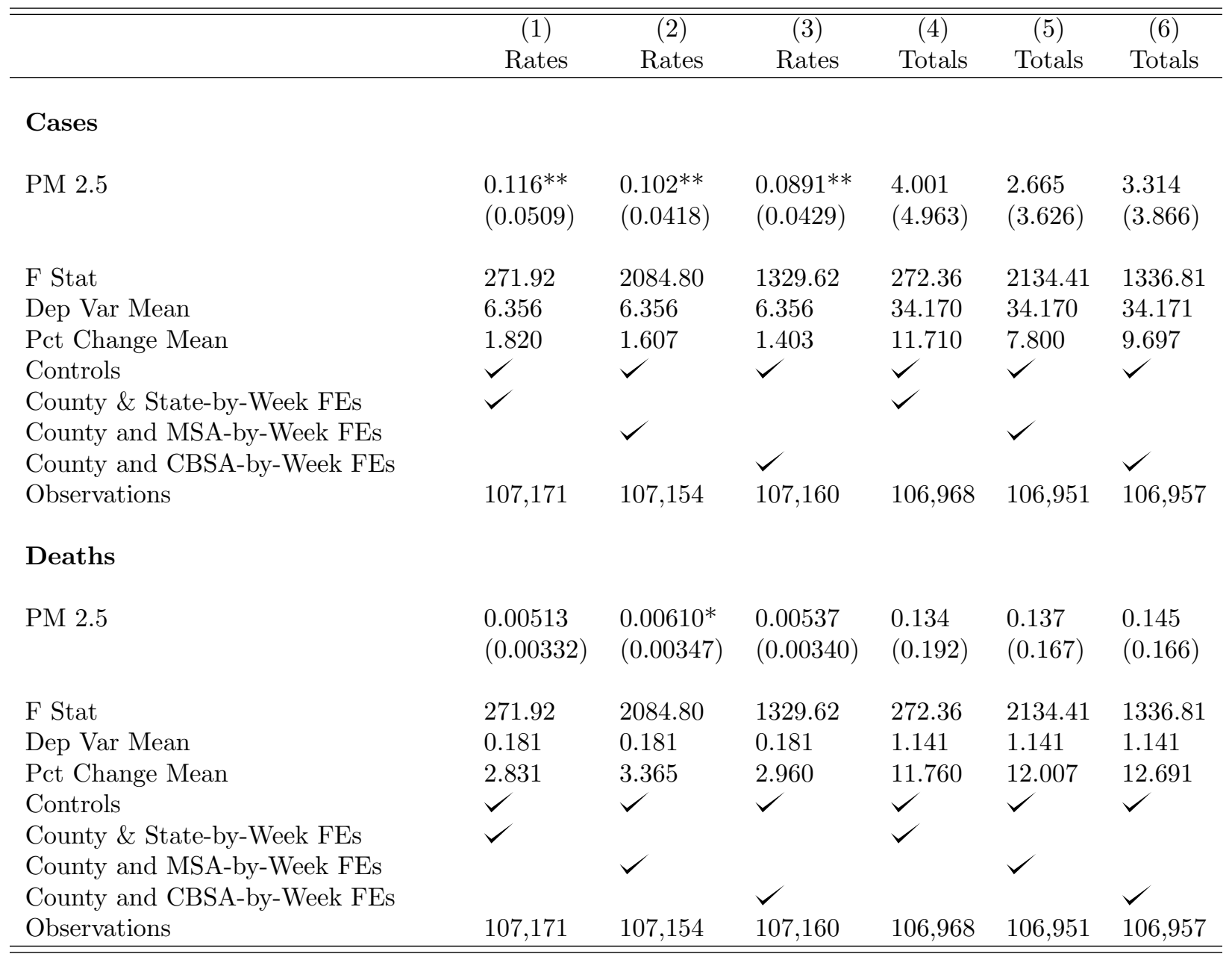

${ }^{*} p<0.1,{ }^{* *} p<0.05,{ }^{* * *} p<0.01$. Standard errors clustered at the county in parentheses. Controls include state-level policy adoption, wind speed dummies, day-of-week dummies, social distancing information, and two lagged wind direction by monitor cluster dummies. Regressions on counts use county population as analytic weights. Displayed output of a two stageleast squares regression model with county and state-by-week, MSA-by-week, or CBSA-by-week fixed effects in which wind direction and location interactions are used to predict PM 2.5 levels in a county on a given day. Fitted pollution values are then used to predict county-level COVID-19 cases and deaths. F statistics computed assuming first-stage standard errors are heteroskedastic. 